\title{
Engaging inexpensive hands-on activities using Chlamydomonas reinhardtii (a green micro-alga) beads to teach the interplay of photosynthesis and cellular respiration to K4 - K16 Biology students
}

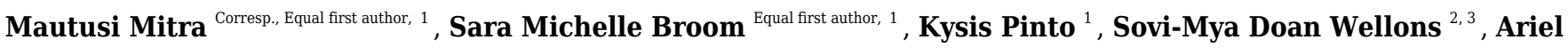 \\ Dominique Roberts ${ }^{1}$ \\ ${ }^{1}$ Biology Department, University of West Georgia, Carrollton, Georgia, USA \\ 2 The Heritage School, Newnan, Georgia, USA \\ 3 Department of Biological Sciences, Dartmouth College, Hanover, New Hampshire, United States \\ Corresponding Author: Mautusi Mitra \\ Email address: mmitra@westga.edu
}

Background. Photosynthesis and cellular respiration play major roles in energy metabolism and are important Life Science topics for K16 Biology students. Algae beads are used for photosynthesis and cellular respiration labs. Currently there are a few companies that sell biology educational kits for making algae beads using non-motile green micro-algae to introduce students to photosynthesis. These kits are expensive and, do not come with detailed guidelines for trouble shooting and customizations for different grade levels. Chlamydmonas reinhardtii is a motile green micro-alga and is an excellent model system for photosynthesis studies. In this article, we are presenting the work conducted in the student-driven, American Society of Plant Biologists-funded, Plant-BLOOME educational outreach project. This project is a supervised collaborative effort of three undergraduates and one high school student. We have generated a protocol which can be used to make Chlamydomonas beads. We have used these beads to design two simple and inexpensive plant biology hands-on activities. These laboratory activities have been customized to teach the interplay of photosynthesis and cellular respiration to K4 - K16 Biology students.

Methods Chlamydomonas beads were used for two different laboratory activities that involved monitoring $\mathrm{pH}$ changes over time using a $\mathrm{pH}$ indicator. Our first activity centers on making and, using light-powered algae bead bracelets to monitor dramatic color/pH changes over time when exposed to darkness or light. Our second activity employs strain-specific algae beads with approximately equal cell numbers to conduct comparative photosynthesis and cellular respiration studies in two Chlamydomonas strains namely, wild type, 4A+ and, a high light-sensitive, photosynthetic mutant, 10E35//sr1a.

Results. We optimized our experimental protocol using algae beads in a $5.5 \mathrm{~mL}$ screw capped glass vials before performing the same experiment in algae bead bracelets. We found that the algal cell density/bead, water type used in the experiment and, the duration of dark exposure of algal beads can affect successful implementation of the lab activities. Light-powered algae bead bracelets showed dramatic color/pH change within 3 hours upon exposure to light or darkness. These bracelets could be switched back and forth between darkness and light multiple times within 48-72 hours to display color/pH changes, provided prior dark exposure time did not exceed 9 hours. Our comparative studies of photosynthesis and cellular respiration in 10E35 and in 4A+ showed that relative respiration rate and photosynthetic rate is higher and lower in 10E35, respectively, compared to that in $4 \mathrm{~A}+$. Additionally, 10E35 failed to display the expected photosynthesis-induced $\mathrm{pH} / \mathrm{color}$ changes in the light after

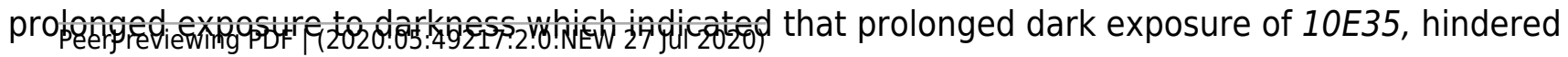


photosynthesis.

Peer] reviewing PDF | (2020:05:49217:2:0:NEW 27 Jul 2020) 
1 Engaging inexpensive hands-on activities using

2 Chlamydomonas reinhardtii (a green micro-alga)

3 beads to teach the interplay of photosynthesis and

4 cellular respiration to K4 - K16 Biology students.

5

6

7

8

9

10

11

12

13

14

15

16

17

18

19

20

21

22

23

24

25

26

27

28

29

30

31

32

33

34

35

36

37

38

Mautusi Mitra ${ }^{1}$, Sara Michelle Broom ${ }^{1}$, Kysis Pinto ${ }^{1}$, Sovi-Mya Doan Wellons ${ }^{2,3}$, Ariel

Dominique Roberts ${ }^{1}$

${ }^{1}$ Biology Department, University of West Georgia, Carrollton, Georgia, USA

2 The Heritage School, Newnan, Georgia, USA

${ }^{3}$ Department of Biological Sciences, Dartmouth College, Hanover, New Hampshire, USA

Corresponding Author:

Mautusi Mitra ${ }^{1}$

1601 Maple Street, Carrollton, Georgia, 30118, USA

Email address:mmitra@westga.edu

\section{Abstract}

Background. Photosynthesis and cellular respiration play major roles in energy metabolism and are important Life Science topics for K16 Biology students. Algae beads are used for photosynthesis and cellular respiration labs. Currently there are a few companies that sell biology educational kits for making algae beads using non-motile green micro-algae to introduce students to photosynthesis. These kits are expensive and, do not come with detailed guidelines for trouble shooting and customizations for different grade levels. Chlamydmonas reinhardtii is a motile green micro-alga and is an excellent model system for photosynthesis studies. In this article, we are presenting the work conducted in the student-driven, American Society of Plant Biologistsfunded, Plant-BLOOME educational outreach project. This project is a supervised collaborative effort of three undergraduates and one high school student. We have generated a protocol which can be used to make Chlamydomonas beads. We have used these beads to design two simple and inexpensive plant biology hands-on activities. These laboratory activities have been customized to teach the interplay of photosynthesis and cellular respiration to K4 - K16 Biology students.

Methods Chlamydomonas beads were used for two different laboratory activities that involved monitoring $\mathrm{pH}$ changes over time using a $\mathrm{pH}$ indicator. Our first activity centers on making and, using light-powered algae bead bracelets to monitor dramatic color/pH changes over time when exposed to darkness or light. Our second activity employs strain-specific algae beads with approximately equal cell numbers to conduct comparative photosynthesis and cellular respiration 
39

40

41

42

43

44

45

46

47

48

49

50

51

52

53

54

55

56

57

58

59

60

61

62

63

64

65

66

67

68

69

70

71

72

73

74

75

76

77

78

studies in two Chlamydomonas strains namely, wild type, 4A+ and, a high light-sensitive, photosynthetic mutant, 10E35/lsrla.

Results. We optimized our experimental protocol using algae beads in a $5.5 \mathrm{~mL}$ screw capped glass vials before performing the same experiment in algae bead bracelets. We found that the algal cell density/bead, water type used in the experiment and, the duration of dark exposure of algal beads can affect successful implementation of the lab activities. Light-powered algae bead bracelets showed dramatic color/pH change within 3 hours upon exposure to light or darkness. These bracelets could be switched back and forth between darkness and light multiple times within 48-72 hours to display color/pH changes, provided prior dark exposure time did not exceed 9 hours. Our comparative studies of photosynthesis and cellular respiration in 10E35 and in $4 \mathrm{~A}+$ showed that relative respiration rate and photosynthetic rate is higher and lower in $10 E 35$, respectively, compared to that in $4 \mathrm{~A}+$. Additionally, $10 E 35$ failed to display the expected photosynthesis-induced $\mathrm{pH} /$ color changes in the light after prolonged exposure to darkness which indicated that prolonged dark exposure of $10 E 35$, hindered photosynthesis.

\section{Introduction}

Photosynthesis, an energy requiring anabolic process, comprises of two sets of reactions that occur in the chloroplast: Light reaction and Calvin cycle. In the light reaction, solar energy captured by photosynthetic pigments is used to photolyze water into electrons and protons. These protons and electrons are ultimately used to generate ATP (adenosine triphosphate), a reducing power and oxygen in the light reaction (Tymoczko, Berg \& Stryer, 2015). ATP and the reducing power generated in the light reaction and water, are used in the Calvin cycle to reduce atmospheric carbon dioxide to sugar (Tymoczko, Berg \& Stryer, 2015). Aerobic cellular respiration is a catabolic energy releasing process that oxidizes fixed carbon to generate ATP (Tymoczko, Berg \& Stryer, 2015). Oxygenic photosynthesis provides not only fixed carbon that is utilized by cellular respiration for energy production but, it is also the only source for generation of oxygen on a mass scale on Earth to support life (Tymoczko, Berg \& Stryer, 2015). Hence, every Biology students should have a broad understanding of these two complementary, life-supporting, fundamental biochemical reactions. These two biochemical reactions are listed in the Next Generation Science Standards (NGSS) Life Science core idea LS1C: From Molecules to Organisms: Structures \& Processes. LS1C aligns with principles 1, 2, 3, 5, 10 and 11 of the 12 Principles of Plant Biology listed by the American Society of Plant Biologists ("The 12 Principles of Plant Biology", ASPB; Article S1).

Guidelines for photosynthesis and cellular respiration laboratories using non-motile green microalgae beads are available on the websites of Carolina Biological (Burlington, NC), Bio-Rad (Hercules, CA) and Gene Technology Access Center (GTAC; Victoria, Australia) for classroom use. ("Carolina Quicktips Making Algae Beads", Carolina Biological; "Photosynthesis and Cellular Respiration Kit for General Biology", Bio-Rad; "Algae Immobilised in Alginate balls", GTAC, 2016). Traditionally, non-motile algae like Chlorella, Ankistrodesmus and Scenedesmus 
79 have been used to generate algae beads as non-motile algae can be trapped and immobilized

80 easily ("Carolina Quicktips Making Algae Beads", Carolina Biological; "Algae Immobilised in 81 Alginate balls", GTAC, 2016; "Photosynthesis and Cellular Respiration Kit for General

82 Biology", Bio-Rad). Chlamydomonas reinhardtii is motile green micro-alga and is an excellent 83 model system for photosynthesis and bioenergy researchers (Merchant et al., 2007; Scranton et 84 al., 2015; Radakovits et al., 2010). At our research laboratory we use Chlamydomonas as an 85 experimental system to study photo-protection and photosynthetic pigment metabolism. Our 86 ASPB-funded Plant-BLOOME educational outreach student-driven project centers on designing 87 new educational hands-on activities using exclusively, Chlamydomonas and not any other alga. 88 There is one recent report of immobilization of a Chlamydomonas strain for photobiohydrogen 89 production under anaerobic sulfur-deprived conditions in different types of photobioreactors 90 (Canbay, Kose \& Oncel, 2018). Low yield of biofuel from large-scale algal cultures in 91 bioreactors is a major problem. Sustainable bioenergy production can be improved by 92 immobilizing motile algae like Chlamydomonas and Botryococcus sp. that are employed for 93 bioenergy research (Canbay, Kose \& Oncel, 2018; Radakovits et al., 2010).

94 Our educational trips to schools in Georgia and our participation at the education booths at the 95 NSTA meeting in Atlanta in 2018 and at the Plant Biology 2019 in San Jose, CA, clearly showed 96 us that K6- K16 students (and even educators) love to make algae beads (Text S1). Bead-making 97 activity is excellent for student engagement in classrooms, which cannot be achieved by using 98 commercially purchased pre-made beads. Unfortunately, anonymous teacher and student surveys 99 that we collected cannot be shared with public because our institution did not submit IRB 100 application materials for this project. Glimpses of our educational outreach activities can be 101 found at several available links shown in Text S1.

102 Commercial kits from Bio-Rad or other vendors are costly when one considers how many 103 students can be served per commercial kit and the duration of the time the kit can be used in classrooms (see Materials and Methods and Text S2 for detailed calculation). Commercial educational kits often do not work well, uses beads with short shelf lives, takes long time to show color change and, sometimes comes with erroneous instructions (For example: Carolina instruction sheet instructs educators to grow dense cultures of Chlorella for 3-4 weeks before harvesting cells for bead-making. This means the company is instructing educators to make algal beads using a culture that is in the late stationary phase; https://www.carolina.com/pdf/activitiesarticles/carolina-qt-making-algae-beads-cb814921806.pdf). Technical resources that comes with these kits lack specific guidelines for optimizing the experiment and troubleshooting. Hence a

112 well-defined protocol with proper detailed guidelines for conducting lab activities \& managing 113 class times and, information for acquiring lab materials inexpensively, will be useful Biology 114 educators at schools and institutions that have very limited resources and funding.

115 Calcium alginate is used to trap and immobilize living cells in industrial procedures ("Carolina 116 Quicktips Making Algae Beads, Carolina Biological; "Algae Immobilised in Alginate balls”, 117 GTAC, 2016; "Photosynthesis and Cellular Respiration Kit for General Biology", Bio-Rad). For 118 example, immobilized non-motile colonial algae are being tested for biofuel production, 
119 immobilized yeast cells are being used for alcoholic wine fermentation, and immobilized 120 bacterial cells are being used for water disinfection (Kröger \& Müller-Langer, 2012; Gotovtsev 121 et al., 2015). To entrap algae in beads, cell suspension and $2 \%$ sodium alginate are mixed at a specific ratio and added drop-wise to chilled calcium chloride solution. Calcium ions link the

123

124

125

126

127

128

129

130

131

132

133

134

135

136

137

138

139

140

141

142

143

144

145

146

147

148

149

150

151

152

153

154

155

156

157

158 alginate monomers together to make a gel-like polymer of calcium alginate which trap cells and immobilize them in beads. These algal beads can be used for biological experiments or other biotechnological applications.

Cellular respiration oxidizes organic chemicals and releases $\mathrm{CO}_{2}$ into the environment irrespective of presence/absence of light and, photosynthesis converts $\mathrm{CO}_{2}$ into fixed carbon only in the presence of light (Tymoczko, Berg \& Stryer, 2015). Cellular respiration in live cells in the beads will release $\mathrm{CO}_{2}$ that will dissolve in water in which the beads are immersed to generate carbonic acid ("Photosynthesis and Cellular Respiration Kit for General Biology", Bio-Rad; "Algae Immobilised in Alginate balls", GTAC, 2016). Conversely in the light, photosynthesis in the algal cells in the beads will remove $\mathrm{CO}_{2}$ from the water surrounding the beads ("Photosynthesis and Cellular Respiration Kit for General Biology", Bio-Rad; "Algae Immobilised in Alginate balls", GTAC, 2016). In the light, cellular respiration is still going on in the cells, but the net use of $\mathrm{CO}_{2}$ by photosynthesis vastly outweighs the $\mathrm{CO}_{2}$ released during cellular respiration, unlike that in the dark. Hence $\mathrm{pH}$ of the water will be acidic in the dark and alkaline in the light. In the two activities designed by us, students will monitor photosynthesis and cellular respiration-induced $\mathrm{pH}$ changes in the water by color changes of a $\mathrm{pH}$ indicator as well as by measuring the $\mathrm{pH}$ with $\mathrm{pH}$ testing strips and/or a $\mathrm{pH}$ electrode.

We have generated a detailed protocol of making Chlamydomonas beads and two simple plant biology hands-on activities. These laboratory activities were used to teach the interplay of photosynthesis and cellular respiration to Biology students in nine schools and two universities in Georgia in a fun and engaging way. The presented educational work is a product of supervised collaborative efforts of three undergraduate students and one high school student in Georgia, USA. In the two designed laboratory activities students make Chlamydomonas beads and use these beads to conduct their own independent experiments. In the first lab activity students make light-powered green algae bead bracelets and use these algae bracelets to perform time course experiments in light and dark to study the interplay of photosynthesis and cellular respiration. In the second activity, students compare relative ratios of photosynthesis and cellular respiration in a Chlamydomonas wild type (4A+) and a chlorophyll-deficient, high-light sensitive mutant strain, 10E35/lsrla, using strain-specific algae beads. 10E35 is a random insertional mutant generated by our research lab with a mutation in a novel functionally uncharacterized gene, LSR1 and is the center of an on-going research project at our laboratory [Nguyen et al., 2017; Article S2].

We present in this article our protocol for making Chlamydomonas beads (including some preliminary testing data that helped us to refine the protocol), two new plant biology teaching tools and sample teaching resources for educators. We hope that the teaching resources will help plant biology educators to customize the labs according to grade level, availability of resources, 
159

160

161

162

163

164

165

166

167

168

169

170

171

172

173

174

175

176

177

178

179

180

181

182

183

184

185

186

187

188

189

190

191

192

193

194

195

196

197

and allow better time management in classrooms. The designed lab activities support active learning and contributes toward the following: 1) NGSS Science and Engineering Practice: Developing and using models; Planning and carrying out investigations and, 2) NGSS Core Idea: Life Science LS1C: From molecules to organisms: Structures and Processes.

\section{Materials \& Methods}

\section{Material information for educators}

Information (vendors and catalog numbers) for ordering specific items related to the project like algal strains, algal growth media, inoculating loops, flasks, plastic transfer pipettes, Eppendorf tubes, $\mathrm{pH}$ indicators, $\mathrm{pH}$ test strips, bracelet tubing, glass vials, yarns for bracelet braids, sodium alginate, calcium chloride, counting chambers etc. are given on pages 1-6 in Text S2 file. On pages 5-6 in Text S2 file, we have shown the pricing of the basic items that one will need to start the lab and the cost comparison of our protocol Vs. the Bio-Rad Photosynthesis and Cellular respiration kit for general Biology. The cost comparison shows that our protocol is inexpensive and will serve more students over a longer period than the Bio-Rad kit (Text S2).

\section{Algal media and cultures}

Chlamydomonas wild type strain 4A+ (CC- $40514 \mathrm{~A}+\mathrm{mt}+)$ strain was a gift from Dr. Krishna K. Niyogi (UC Berkeley, CA). 10E35/lsr la (light-sensitive related 1a) is a random insertional nuclear mutant generated by our lab which has a mutation in a novel gene, LSR1 encoding a protein of unknown function [Nguyen et al., 2017; Article S2]. 4A+ and 10E35 strains were maintained in the lab on Tris- $\underline{\text { Acetate }}$ Phosphate (TAP) agar media plates (Text S2) in dim light intensities $\left(15-20 \mu \mathrm{mol} \mathrm{m}^{-2} \mathrm{~s}^{-1}\right)$ at $25^{\circ} \mathrm{C}$. A starter culture of $4 \mathrm{~A}+$ was started approximately $11-12$ days ahead of the lab activity by inoculating $10 \mathrm{~mL}$ of liquid TAP media in a $50 \mathrm{~mL}$ flask with $4 \mathrm{~A}+$ cells from a 5 -day old TAP agar media plate (Text S2). After 5 days of growth, $1 \mathrm{~mL}$ of the starter culture was used to inoculate $300 \mathrm{~mL}$ of fresh TAP media in a $1 \mathrm{~L}$ flask. The TAP liquid $4 \mathrm{~A}+$ culture was grown for 6-7 days for dense dark green growth. 10E35 grows slower than $4 \mathrm{~A}+$. Hence $10 E 35$ liquid TAP cultures should be started at least 3-4 days before starting the $4 \mathrm{~A}+$ liquid TAP cultures. Algal liquid cultures were grown under $25^{\circ} \mathrm{C}$ under continuous illumination of 80-100 $\mu \mathrm{mol}$ photons $\mathrm{m}^{-2} \mathrm{~s}^{-1}$ provided by the combined light intensities of four to six cool white fluorescent lights. Cultures were shaken continuously on an open-air orbital shaker at a speed of 150-180 rpm to ensure a uniform illumination of the cells and to prevent cells from settling down. Light intensities were measured using a LI-250A Light Meter (LICOR, Inc., Lincoln, NE).

\section{Preparation of $2 \%$ sodium alginate and $3 \%$ calcium chloride solutions}

2 grams of sodium alginate (Fisher Scientific, Waltham, MA) was dissolved in $100 \mathrm{~mL}$ of E-pure water overnight at room temperature by stirring at a speed of $400 \mathrm{rpm}$ using a magnetic stirrer. [Note: sodium alginate forms a very viscous solution when dissolved at $1.5 \%-4 \%$ ]. $2 \%$ sodium alginate solution was stored at room temperature. 30 grams of calcium chloride was dissolved in $1000 \mathrm{~mL}$ of E-pure water and stored at $4^{\circ} \mathrm{C}$ in a fridge. 


\section{Cell counts}

199 Cell density (number of cells per mL of the culture) was determined before harvesting

200 Chlamydomonas cells from the TAP liquid culture to estimate the volume of culture needed to

201 harvest specific number of cells per $50 \mathrm{~mL}$ falcon tube. Cell density was calculated by counting

202 the cells using a Hausser Scientific Bright-Line ${ }^{\mathrm{TM}}$ Counting Chamber (Hausser Scientific,

203 Philadelphia, PA). A basic protocol on how to use a hemocytometer in a classroom setting is

204 available at https://www.ruf.rice.edu/ bioslabs/methods/microscopy/cellcounting.html. It is to be

205 noted that cell counting is optional. School teachers who do not have access to a

206 hemocytometer/counting chamber, can grow algae culture for 6-7 days and then harvest the cells

207 to make beads. Additionally, teachers can match the green color of the beads with that shown in

208 our article figures.

209 Preparation of Chlamydomonas 4A+ and 10E35 beads

210 A detailed version of the Chlamydomonas bead-making protocol (including trouble shooting) is

211 available at https://www.protocols.io/view/making-inexpensive-light-powered-chlamydomonas-

212 rei-bgpyjvpw. Chlamydomonas strain 4A+ or $10 E 35$ cells were harvested by spinning down

213 dense TAP liquid strain-specific cultures at 1,000-1,500 g for 3 minutes in a benchtop centrifuge.

214 The supernatant was discarded and the cell pellet was collected. Harvesting $100 \mathrm{~mL}$ of dense

215 Chlamydomonas culture generated 200-300 beads of 4-5 $\mathrm{mm}$ in diameter. $\%$ well mixed-

216 sodium alginate was added to the cell pellet in a 4:1 or 5:1 ratio (depending on the total number

217 of cells harvested; see results and detailed protocol on https://www.protocols.io/view/making-

218 inexpensive-light-powered-chlamydomonas-rei-bgpyjvpw). The algae and 2\% sodium alginate

219 were gently mixed till the entire cell pellet was completely resuspended without any visible cell

220 clumps. Maximum number of total cells used for resuspension in sodium alginate was either 395

$221 \times 10^{6}$ or $790 \times 10^{6}$ cells depending on the experiment (see result section). We resuspended the

222 cell pellets containing $395 \times 10^{6}$ cells and $790 \times 10^{6}$ cells in $5 \mathrm{~mL}$ of sodium alginate to get an

223 approximate final cell density of $66 \times 10^{6}$ cells $/ \mathrm{mL}$ and $132 \times 10^{6}$ cells $/ \mathrm{mL}$ in the cell

224 suspension, respectively. $1 \mathrm{~mL}$ of sodium alginate-algal cell suspension gave us approximately

225 32-35 beads depending on pipetting techniques. Hence the cell suspension with cell density of 66

$226 \times 10^{6}$ cells $/ \mathrm{mL}$ will form beads that have approximately $1.89 \times 10^{6}-2 \times 10^{6}$ cells/bead while the

227 cell suspension with cell density of $132 \times 10^{6}$ cells $/ \mathrm{mL}$ will have $3.77 \times 10^{6}-4.1 \times 10^{6}$

228 cells/bead. We used 8 beads of similar sizes (4-5 $\mathrm{mm}$ in diameter) for glass vial experiments.

229 The algae-sodium alginate mix was added drop wise steadily and quickly with uniform pipetting

230 by using a micropipette or a plastic transfer pipette into a beaker of pre-chilled $3 \%$ calcium

231 chloride kept on ice. If pipetting is not smooth and regular and, the algae-sodium alginate

232 mixture is not mixed by swirling in between pipetting, irregular shaped and beads with different

233 cell numbers/bead (light and dark green beads) will form (Fig. S1). As soon as the algae-sodium

234 alginate mixture touches the chilled calcium chloride liquid surface, the mixture solidified into

235 tiny beads. The calcium chloride beaker containing the beads were kept on ice for 10-15 minutes

236 to allow complete solidification of the algal beads. 
237 The beads are separated from the calcium chloride solution by filtering through an oil strainer. 238 Algal beads on the strainer were washed with tap water. The beads were kept temporarily in a 239 petri dish containing small amount of tap water till the bracelets were made. Surplus beads were 240 stored in tap water in a beaker for future use within 1-2 days. Algae bead making demonstration 241 video clips are available at: https://youtu.be/u4BbZ29qlWQ and at

242 https://youtu.be/eIxbzeHW8IM.

\section{Preparation of Chlamydomonas $\mathbf{4 A}+$ bead bracelet}

244 Flexible tubing was cut into 10 pieces, each 5 inches long. Caps of $1.5 \mathrm{~mL}$ Eppendorf tubes were

245

246

247

248

249

250

251

252

253

254

255

256

257

258

259

260

261

262

263

264

265

266

267

268

269

270

271

272

273

274

275

276

277

278 cut off with a scissor. De-capped Eppendorf tube was used to plug the ends of the bracelet tubing (one de-capped tube at each end of the cut tubing). Colorful cotton yarn was cut according to the wrist width, intertwined and yarn braids were made. One braid was looped tightly onto the mouth of each de-capped Eppendorf tube at each end of the bracelet. Next, one end of the bracelet tubing was unplugged by removing the de-capped Eppendorf tube that was sealing the end. About $3.5 \mathrm{~mL}$ of tap water [pH 7.2 -7.3] was introduced into the bracelet flexible tubing. 15- 38 algae beads (depending on the experiment) were gently introduced into the water inside the tubing. 8-10 drops of the bicarbonate indicator (Carolina Biological, Burlington, NC) were added into the water in the tubing and the end of the tubing was plugged back with the de-capped Eppendorf tube. Precautions were taken to avoid acidic or alkaline contamination of the flexible tubing, plastic spoon, transfer pipettes, petri dishes etc. used in our experiments, since the bicarbonate indicator is not directly specific to gases like carbon dioxide. About $0.5 \mathrm{~cm}-1 \mathrm{~cm}$ air gap was left at each end inside the tubing to provide enough air for cells. The bracelet was imaged and the $\mathrm{pH}$ of the water inside the bracelet was measured using $\mathrm{pH}$ testing strips (Fisher Scientific, Waltham, MA) before shifting it to light or to darkness for the lab activity. All experiments described below were performed with the same batch of beads. A detailed version of the protocol is available at https://www.protocols.io/view/making-inexpensive-light-poweredchlamydomonas-rei-bgpyjupw. Demonstration of algae bead bracelet making video clips available at: https://youtu.be/A7VIjLDGSCc and https://youtu.be/vh 1ASpQgS8 and https://youtu.be/enctr0yhWQ8.

\section{Light and dark exposure experiments with Chlamydomonas bead bracelets}

For the constant light/dark exposure experiment, one bracelet was kept under 150-200 $\mu$ mole $\mathrm{m}^{-}$ ${ }^{2} \mathrm{~S}^{-1}$ light intensity [equivalent to the combined light intensities of 12 to 14 cool white fluorescent lights] and another one was kept in the dark inside a lab cabinet drawer. After 3 hours of light/dark exposure, bracelets were imaged. $\mathrm{pH}$ of the water inside the bracelets were measured using $\mathrm{pH}$ testing strips (Fisher Scientific, Waltham, MA).

For dark shift experiment, the bracelet was first light-adapted for 4 hours and then shifted to darkness. For light shift experiment, the bracelet was dark-adapted for 4 hours and then shifted to light. After every 1 hour over a period of 4 hours during light exposure or over a period of 3 hours during dark exposure, the bracelet was imaged to monitor the carbon dioxide percentage change inside the bracelet tubing. The carbon dioxide percentage change is monitored indirectly by the color changes of the bicarbonate indicator. $\mathrm{pH}$ was not measured for the light/dark shift experiments with algae bead bracelets. For testing the effect of different dark exposure times on photosynthesis, one algae bead bracelet was exposed to 9 hours of darkness and the other was 
279 exposed to 15 hours of darkness. After the dark exposure, the 9 hours- and 15 hours- dark280 adapted bracelets were exposed to light for 4 hours and 12 hours, respectively and were imaged 281 after the light exposure. $\mathrm{pH}$ of the water inside these light and dark-exposed bracelets was 282 measured using $\mathrm{pH}$ testing strips (Fisher Scientific, Waltham, MA).

283

284

285

286

287

288

289

290

291

292

293

294

295

296

297

298

299

300

301

302

303

304

305

306

307

308

309

310

311

312

313

314

315

316

317

318

\section{Light and dark exposure experiments with Chlamydomonas strain-specific beads in glass vials}

For testing the effect of water quality on photosynthesis, eight $4 \mathrm{~A}+$ beads were either introduced into $2.5 \mathrm{~mL}$ of tap water (pH 7.2 -7.3) or into de-ionized [DI] water (pH 7.1-7.2) in 5.5 mL screw capped glass vials (Fisher Scientific, Waltham, MA). For testing the effect of cell density on photosynthesis, eight $4 \mathrm{~A}+$ beads were either introduced into $2.5 \mathrm{~mL}$ of tap water (pH 7.2 -7.3). For both stated experiments, $125 \mu \mathrm{L}$ of the $0.02 \%$ phenol red solution (Fisher Scientific, Waltham, MA) was added to the algae bead vials to serve as a $\mathrm{pH}$ indicator and the vials were capped tightly. One set of $4 \mathrm{~A}+$ bead and the control vials were exposed to $150-200 \mu \mathrm{mole} \mathrm{m}^{-2} \mathrm{~s}^{-1}$ light intensity and the other set to darkness for 2 hours. After 2 hours of light or dark exposure, vials were imaged and $\mathrm{pH}$ of the water in the vials was measured using a Thermo Fisher Scientific Orion-3 Star benchtop pH meter (Fisher Scientific, Waltham, MA).

For comparative analyses of photosynthesis and cellular respiration in $4 \mathrm{~A}+$ and $10 E 35$ strains under constant light/darkness, beads having approximately $2 \times 10^{6} \mathrm{cells} / \mathrm{bead}$ for each strain were used (Fig. S2). Eight $4 \mathrm{~A}+$ and $10 E 35$ beads were introduced into $2.5 \mathrm{~mL}$ of tap water (pH $6.9-7.3$ ) in $5.5 \mathrm{~mL}$ screw capped glass vials (Fisher Scientific, Waltham, MA). $125 \mu \mathrm{L}$ of the phenol red solution (Fisher Scientific, Waltham, MA) was added to the $4 \mathrm{~A}+$ and $10 E 35$ bead vials and the vials were capped tightly. One set of $4 \mathrm{~A}+, 10 E 35$ and control vials was exposed to light intensity of 150-200 $\mu \mathrm{mole} \mathrm{m}^{-2} \mathrm{~s}^{-1}$ and the other set was exposed to darkness for 1 hour. The algae bead and control vials were imaged after every 30 minutes over a period of 1 hour and $\mathrm{pH}$ of the water in the vials was measured. The 1-hour light adapted $4 \mathrm{~A}+, 10 E 35$ and the control vials were exposed to light for an additional 3 hours and then shifted to dark. The vials were imaged after every 15 minutes for a period of 1 hour during dark exposure. After 1 hour, these dark-exposed vials were kept under dark for additional 5 hours. After 6 hours-of dark exposure, vials were shifted to light $\left[150-200 \mu\right.$ mole $\left.\mathrm{m}^{-2} \mathrm{~s}^{-1}\right]$ and imaged after 30 minutes, 1 hour, 2 hours, 3 hours and 48 hours. $\mathrm{pH}$ of the water in the glass vials in the above stated experiments were measured using a Thermo Fisher Scientific Orion-3 Star benchtop pH meter (Fisher Scientific, Waltham, MA).

\section{Imaging and Data analyses}

Images were captured a Samsung Galaxy S5 camera. Statistical analyses of the recorded $\mathrm{pH}$ data were performed using Microsoft Excels' t-Test: Paired Two Sample for Means tool in the analysis ToolPak. Both One-Tailed and Two-Tailed Hypothesis Tests were performed. Standard deviations shown in Tables under result section was calculated using Excel. Raw statistical analyses data from three biological replicates per experiment have been deposited in Figshare (https://doi.org/10.6084/m9.figshare.12344024.v1) and are presented in the supplementary Data S1 file. p-values of experiments can be found in the Data S1 file. Data S2 file contains raw pH 
322

323

324

325

326

327

328

329

330

331

332

333

334

335

336

337

338

339

340

341

342

343

344

345

346

347

348

349

350

351

352

353

354

355

356

357

data, mean and standard deviation information. Each biological replicate had three internal replicates. The average of three internal replicates from each biological replicate is shown in the data in Data S1 and Data S2 files.

\section{Results}

\section{Photosynthesis and cellular respiration-induced pH changes in de-ionized (DI) water and} tap water vials containing Chlamydomonas $4 \mathrm{~A}+$ strain beads.

DI water is known to contain less dissolved gases and minerals than tap water ["The Lab Depot, What is Pure Water?"; Whitehead, 2020]. Amounts of dissolved oxygen and carbon-dioxide in the water used for photosynthesis monitoring experiment will affect the results in a photosynthesis lab. Hence, we monitored photosynthesis and cellular respiration of the wild type Chlamydomonas strain, 4A+ beads in DI water and in tap water to see which one would be suitable for designing the photosynthesis lab (Fig. 1; Table S1). The $\mathrm{pH}$ indicator phenol red exhibits a gradual transition from light orange to red over the $\mathrm{pH}$ range 6.8 to 8.2 . Phenol red turns yellow below pH 6.7 and turns to a bright pink (fuchsia) color above pH 8.2. The expected color scale at different $\mathrm{pH}$ when phenol red is used as the $\mathrm{pH}$ indicator can be found at https://commons.wikimedia.org/wiki/File:Phenol red pH 6,0 - 8,0.jpg and at https://en.wikipedia.org/wiki/Phenol red.

Our results show that there was no statistically significant difference in the water color or $\mathrm{pH}$ between the control and experimental vials containing de-ionized water in the light and in the dark ( $p$ values from the 1-tailed and 2-tailed hypothesis tests for the light set samples were 0.21 and 0.42 , respectively; $p$ values from the 1-tailed and 2-tailed hypothesis tests for the dark set samples were 0.09 and 0.18 , respectively; Fig. 1A; https://doi.org/10.6084/m9.figshare.12344024.v1; Data S1; Data S2). There was no significant difference in $\mathrm{pH}$ in the control vials with $\mathrm{DI}$ and tap water under light and dark ( $\mathrm{p}$-values for the control light samples from the 1-tailed and 2-tailed hypothesis tests were 0.11 and 0.22 , respectively; $\mathrm{p}$-values for the control dark samples from the 1-tailed and 2-tailed hypothesis tests were 0.09 and 0.18, respectively; Data S1). Dark-exposed tap water experimental vial displayed acidic $\mathrm{pH}$ (yellow color) while the light-exposed tap water experimental vial displayed alkaline $\mathrm{pH}$ (fuchsia color) relative to the respective control vials and the $\mathrm{pH}$ difference was statistically significant ( $\mathrm{p}$-values from the 1-tailed and 2-tailed hypothesis tests were 0.0001 and 0.0002 , respectively; Fig.1B; Table S1; https://doi.org/10.6084/m9.figshare.12344024.v1; Data S1, Data S2). There was a difference of approximately $2 \mathrm{pH}$ units between the dark and light-adapted tap water experimental vials in contrast to the $0.07 \mathrm{pH}$ unit difference between the DI water in the dark-and in the light-adapted experimental vials (Table S1;

https://doi.org/10.6084/m9.figshare.12344024.v1; Data S1, Data S2). In the light-exposed tap water algal bead vial, buoyancy of a bead can be seen which is indicative of $\mathrm{O}_{2}$ production in photosynthesis (Fig. 1B). Taken together our results show that tap water is preferable over DI water for performing photosynthesis lab activities. 
358

359

360

361

362

363

364

365

366

367

368

369

370

371

372

373

374

375

376

377

378

379

380

381

382

383

384

385

386

387

388

389

390

391

392

393

394

395

396

397

Effect of total cell numbers in Chlamydomonas $4 \mathrm{~A}+$ strain beads on photosynthesis and cellular respiration-induced color/pH changes in tap water.

We used two types of beads that have two-fold difference in total cell numbers/bead: 1) beads that have approximately $2 \times 10^{6}$ cells/bead and, 2) beads that have approximately $4 \times 10^{6}$ cells/bead. It is expected that a high cell number in a bead will increase cellular respiration as a high cell density in the bead will create oxygen stress. The $\mathrm{pH}$ in the light-exposed vial containing $4 \times 10^{6}$ cells/bead was 6.1 and the $\mathrm{pH}$ in the light exposed vial containing $2 \times 10^{6}$ cells/bead was $\mathrm{pH} 8.4$ for the same duration of light exposure (Fig. 2; Table S2;

https://doi.org/10.6084/m9.figshare.12344024.v1; Data S1; Data S2). The pH in the light- and dark-exposed vials containing $4 \times 10^{6}$ cells/bead differed by only $0.1 \mathrm{pH}$ unit while the $\mathrm{pH}$ in the light- and dark-exposed vials containing $2 \times 10^{6}$ cells/bead differed approximately by $2 \mathrm{pH}$ units for the same duration of light exposure (Fig. 2; Table S2;

https://doi.org/10.6084/m9.figshare.12344024.v1; Data S1; Data S2). There was a statistically significant $\mathrm{pH}$ difference between the light-exposed vials with $4 \mathrm{X} 10^{6} \mathrm{cells} / \mathrm{bead}$ and that with 2 $\mathrm{X} 10^{6} \mathrm{cells} / \mathrm{bead}$ (p-values from the 1-tailed and 2-tailed hypothesis tests for the light-exposed vials were 0.0001 and 0.0002 , respectively; Data S1). The $\mathrm{pH}$ difference between the darkexposed vials with $4 \times 10^{6}$ cells/bead and that with $2 \times 10^{6}$ cells/bead was statistically significant (p-values from the 1-tailed and 2-tailed hypothesis tests were 0.01 and 0.02, respectively; Data S1). $\mathrm{pH}$ differences between the light and dark control vials were insignificant as the p-values were higher than 0.05 in both 1-tailed and 2-tailed hypothesis tests (Data S1). Our results show high cell density/bead will hinder observation of $\mathrm{pH}$ changes in a photosynthesis lab. In the lightexposed experimental vial, partial buoyancy of one bead can be seen, indicative of $\mathrm{O}_{2}$ production in photosynthesis (Fig. 2B).

\section{Indirect detection of carbon dioxide concentration in the $4 \mathrm{~A}+$ bead bracelet under light and} darkness using the bicarbonate indicator.

Bicarbonate indicator is commonly used in photosynthesis and respiration experiments to detect indirectly the percentage of carbon dioxide in a sample. It is a more sensitive $\mathrm{pH}$ indicator than phenol red. When the carbon dioxide content in water is higher than $0.04 \%$, $\mathrm{pH}$ becomes acidic. Acidic $\mathrm{pH}$ changes the red color of the indicator to yellow. If the carbon dioxide content is lower than $0.04 \%$, pH gets alkaline and the indicator changes color from red to magenta and, under very low carbon dioxide concentrations the color of the indicator changes to purple (https://en.wikipedia.org/wiki/Bicarbonate_indicator). The expected color scale at different $\mathrm{pH}$ when bicarbonate indicator is used as the $\mathrm{pH}$ indicator can be found at

https://pmgbiology.com/tag/respiration/.

We used three bracelets (with algal beads ranging from 30-38) to monitor color changes of the bracelet water containing the bicarbonate indicator. These are designated as control, darkexposed and light-exposed bracelets in Fig. 3. The color of the water in the control bracelet (not exposed to dark or light), dark- and light-exposed bracelets were, light red, bright yellow and dark blue, respectively (Fig. 3). The objective of the experiment was to simply determine the color/pH changes of the water in the experimental bracelets in the light or in the dark relative to

Peer) reviewing PDF | (2020:05:49217:2:0:NEW 27 Jul 2020) 
398

399

400

401

402

403

404

405

406

407

408

409

410

411

412

413

414

415

416

417

418

419

420

421

422

423

424

425

426

427

428

429

430

431

432

433

434

435

436

437

the control. The average $\mathrm{pH}$ of the water in the control algal bracelet was around 7 (Fig. 3A; Table S3; https://doi.org/10.6084/m9.figshare.12344024.v1; Data S1; Data S2). pH of the water in the dark-exposed algal bracelets ranged between 6 and 6.5 with STDEV \pm 0.24 (Fig.3B; https://doi.org/10.6084/m9.figshare.12344024.v1; Data S1; Data S2) indicating a high percentage of carbon dioxide because of cellular respiration. $\mathrm{pH}$ of the water in the light-exposed algal bracelets ranged between 8.5 and 9 with STDEV \pm 0.24 indicating a low percentage of carbon dioxide because of photosynthesis (Fig. 3C; Table S3;

https://doi.org/10.6084/m9.figshare.12344024.v1; Data S1; Data S2). pH difference between the light- and dark-exposed bracelets is statistically significant (p-values from the 1-tailed and 2tailed hypothesis tests were 0.001 and 0.003 , respectively; Data S1; Data S2;

https://doi.org/10.6084/m9.figshare.12344024.v1). Our results clearly show that carbon-dioxide percentage can be monitored indirectly under light/darkness via sharp $\mathrm{pH} / \mathrm{color}$ changes in the water in the bracelet in the presence of the bicarbonate indicator.

Time course monitoring of photosynthesis-induced color changes in the dark adapted- $4 \mathrm{~A}+$ bead bracelet when shifted to light.

An algal bracelet was dark-adapted for 4 hours. After dark-adaptation the bracelet was exposed to light for 4 hours. This light-exposed bracelet was imaged after every 1 hour during light exposure to monitor the gradient color changes over time without disturbing the bracelet (Fig. 4). The results show that if the algal bracelet is left undisturbed, one can pinpoint specifically which beads were actively photosynthesizing from the red-magenta-purple color streaks in the water on top of these beads that were removing carbon-dioxide from the tubing water (Fig. 4 B-D). pH was not measured in these bracelets as the objective of this experiment was to determine if differences exist in photosynthetic rates among different beads by visually observing the gradual color change of the water in the bracelet in light.

Time course monitoring of cellular respiration-induced color changes in the light adapted$4 \mathrm{~A}+$ bead bracelet when shifted to darkness.

An algal bracelet was light adapted for 4 hours. After light-adaptation the bracelet was exposed to dark for 3 hours. The dark-exposed bracelet was imaged after every 1 hour during the light exposure to monitor the gradient color changes over time (Fig. 5). The results show that distinct $\mathrm{pH}$ gradient can be observed in a colorful way in an undisturbed algal bracelet (Fig. 5B). pH was not measured in these bracelets as the objective of this experiment (in conjunction with the Fig. 4 experiment) was to teach students in a fun way, the "tug of war" between photosynthesis and cellular respiration by visually observing the dramatic color changes of the water in the bracelet upon exposure to darkness or light.

\section{Effect of prior dark exposure duration on photosynthesis-induced pH changes in the $4 \mathrm{~A}+$} bead bracelet in light.

One algal bracelet was kept in the dark for 9 hours and the other one was kept in the dark for 15 hours. After dark incubation, both bracelets were imaged and the $\mathrm{pH}$ was measured using $\mathrm{pH}$ testing strips and, then shifted to light. (Fig. 6). There was no significant difference in $\mathrm{pH}$ between the 9-hours dark-adapted and 15-hours-dark adapted bracelets ( $\mathrm{p}$ values from 1-tailed 
438

439

440

441

442

443

444

445

446

447

448

449

450

451

452

453

454

455

456

457

458

459

460

461

462

463

464

465

466

467

468

469

470

471

472

473

474

475

476

and 2-tailed tests were 0.11 and 0.22 , respectively; Data S1). There was a significant difference in $\mathrm{pH}$ between 9-hours-dark adapted bracelet and 15-hours-dark adapted bracelet when these were exposed to light for 4 hours and 12 hours, respectively ( $\mathrm{p}$ values from 1-tailed and 2-tailed tests were 0.002 and 0.005 , respectively; Data S1). The bracelet that was kept in dark for 9 hours showed increase in $\mathrm{pH}$ from $\mathrm{pH} 6[\mathrm{STDEV} \pm 0$ ] to $\mathrm{pH} 8.67$ [STDEV \pm 0.24 ] within 4 hours under light because of photosynthesis (Fig. 6A \& 6B; Table S4;

https://doi.org/10.6084/m9.figshare.12344024.v1; Data S1; Data S2). The bracelet that was kept in dark for 15 hours showed a small increase in $\mathrm{pH}$ from 5.5 [STDEV \pm 0.41 ] to 6.3 [STDEV $\pm 0.24]$, despite being exposed to light for 12 hours. This indicates prior prolonged exposure to darkness hinders photosynthesis in algal beads in light (Fig. 6C \& 6D; Table S4; https://doi.org/10.6084/m9.figshare.12344024.v1; Data S1; Data S2).

\section{Comparative studies of photosynthesis and cellular respiration-induced color/pH changes} in vials containing wild type $4 \mathrm{~A}+$ and $10 E 35$ mutant beads.

$4 \mathrm{~A}+$ and $10 E 35$ beads have approximately $2 \times 10^{6}$ cells/bead (Fig. S2). Each light and dark set comprised of a control and experimental vials of $10 E 35$ and $4 \mathrm{~A}+$ (Fig.7). Images of the vials in each light and dark set were taken before light or dark exposure (Fig.7A and 7D). Each light and dark vial sets were imaged after 30 minutes of light and dark exposures, respectively for a period of 1 hour. Results show a statistically significant slow increase in $\mathrm{pH}$ in $10 E 35$ vial under light compared to that in the 4A+ vial (Fig.7B -7C; Table S5;

https://doi.org/10.6084/m9.figshare.12344024.v1; Data S1; Data S2) (p-values from the 1-tailed and the 2-tailed tests ranged from $0-0.015$ and $0-0.03$, respectively). This could be due to a slow rate of photosynthesis or a high rate of cellular respiration or a combination of both phenomena in $10 E 35$ relative to that in $4 \mathrm{~A}+.10 E 35$ displays relatively a higher rate of cellular respiration in dark compared to that in $4 \mathrm{~A}+$ as indicated by the fast $\mathrm{pH}$ drop in dark in $10 E 35$ vial over time compared to that in the $4 \mathrm{~A}+$ vial that is statistically significant (Fig.7E- 7F; Table S5, https://doi.org/10.6084/m9.figshare.12344024.v1; Data S1; Data S2) (p-values from the 1tailed and 2-tailed tests ranged from $0.002-0.011$ and $0.005-0.022$, respectively).

\section{Time course monitoring of cellular respiration-induced color/pH changes in the dark in} vials containing $4 \mathrm{~A}+$ and $10 E 35$ beads that were exposed to light for 4 hours.

\section{Light-exposed 10E35, 4A+ and control vials from Fig. 7 experiment were exposed to light for} additional three hours. Hence this set was light-exposed for a total of 4 hours. After fours of light exposure, images were taken and the vials were exposed to dark. Images of the dark-exposed vials were taken every 15 minutes over a period of 1 hour during dark exposure (Fig. 8). 10E35 shows relatively a higher cellular respiration rate that is statistically significant, compared to that in $4 \mathrm{~A}+$, as indicated by the rapid drop in $\mathrm{pH}$ in the $10 E 35$ vial compared to that in the $4 \mathrm{~A}+$ vial (p-values from the 1-tailed and 2-tailed tests ranged from $0.0005-0.001$ and from $0.001-0.003$, respectively) (Fig. 8B - 8E; Table S6; https://doi.org/10.6084/m9.figshare.12344024.v1; Data $\mathrm{S} 1$; Data S2). The results re-confirm the results shown in Fig. 7E-7F (Table S5, https://doi.org/10.6084/m9.figshare.12344024.v1; Data S1; Data S2).

Peer) reviewing PDF | (2020:05:49217:2:0:NEW 27 Jul 2020) 
477 Time course monitoring of photosynthesis-induced $\mathrm{pH}$ changes in the light in $4 \mathrm{~A}+$ and $47810 E 35$ bead vials that were exposed to dark for 6 hours.

479 Dark-exposed 10E35, 4A+ and control vials from Fig. 8 experiment were exposed to dark for 480 additional five hours. Hence this set was dark-exposed for a total of six hours. After six hours of 481 dark exposure, images were taken of the dark-exposed vials and the vials were exposed to light.

482 Images of these light-exposed vials were taken after 30 minutes, 1 hour, 2 hours, 3 hours and 48

483 hours of light exposure (Fig. 9). The results show that $4 \mathrm{~A}+$ photosynthesized at a faster rate

484 compared to $10 E 35$ after 6 hours of dark exposure to cause a distinct water color/pH change that 485 was statistically significant (p-values from the 1-tailed and 2-tailed tests ranged from 0.0001-

4860.0175 and from $0.0002-0.035$, respectively) (Table S7;

487 https://doi.org/10.6084/m9.figshare.12344024.v1; Data S1; Data S2). Despite the significant $\mathrm{pH}$ 488 difference in these two vials of $10 E 35, \mathrm{pH}$ in the 48 hours-light exposed $10 E 35$ vial was acidic $489(\mathrm{pH}=6.43 \pm 0.06)$ compared to the alkaline $\mathrm{pH}(8.47 \pm 0.06)$ in the 48 hours-exposed $4 \mathrm{~A}+$ vial. It 490 is known that 10E35 progressively photo-bleaches with increase in light intensity [Nguyen et al., 491 2017; Article S2]. Figure 9F shows that 10E35 beads were photo-bleached in the light-exposed 492 vial after 48 hours of light exposure. Photo-bleaching indicates that there is chlorophyll 493 breakdown in the beads.

494 Discussion

495 Chlamydomonas reinhardtii is a unicellular micro-green alga (a Chlorophyte) that retains many 496 of the features of green plants and of the common ancestor of plants and animals, although its 497 lineage diverged from Streptophytes over one billion years ago. Chlamydomonas is used to study 498 eukaryotic photosynthesis because, unlike angiosperms, it can use acetate to grow in the dark 499 while maintaining a functional photosynthetic apparatus (Merchant et al., 2007). It is also a 500 model organism for elucidating eukaryotic flagella and basal body structure and functions which 501 can be linked to various ciliopathies (Silflow \& Lefebvre, 2001). More recently,

502 Chlamydomonas research has been developed for bioremediation purposes, generation of 503 biofuels and has led to breakthroughs in optogenetics (Merchant et al., 2007; "Critical tool for 504 brain research derived from 'pond scum" NSF, 2013; Zhang, 2015; Scranton et al., 2015).

505 Currently, the Chlamydomonas Resource Center [https://www.chlamycollection.org/]

506 offers number of educational kits ("Resources For Teaching" - Chlamydomonas Resource

507 Center") including instructions and strains on its website; however, these tools barely scratch the 508 surface of what could be taught using Chlamydomonas to students enrolled in K12 Biology and 509 in college Biology undergraduate courses. Hence there is a huge potential to develop 510 Chlamydomonas an under-utilized teaching tool, into a powerful popular teaching tool which 511 will complement existing plant science teaching strategies. Our objective for the American 512 Society of Plant Biologists' (ASPB) Plant-BLOOME project was to design fifteen simple hands-

513 on activities on different Biology topics that can not only educate and excite high school students 514 about Chlamydomonas but can be also included as a component in college Biology laboratory 515 courses. The activities described in this manuscript is centered on photosynthesis and cellular 516 respiration. 
517 We have found that the Chlamydomonas culture should be grown under low light (80-100 micro 518 mol photons $\mathrm{m}^{-2} \mathrm{~s}^{-1}$ ) to obtain a healthy culture that is not photo-oxidatively stressed to be used 519 for our lab activities. The culture should be a dense culture and have a cell density ranging from $52018 \times 10^{6}$ cells $/ \mathrm{mL}$ to $22 \times 10^{6}$ cells $/ \mathrm{mL}$ to get enough cells for a class of 24 students, working in 521 groups of two to three. Algal beads once made, should be rinsed thoroughly with tap water for at 522 least five minutes to remove residual sodium chloride that is formed as a product in the reaction 523 between sodium alginate and calcium chloride during bead-making step. This step is a very 524 important step and must not be skipped as any residual sodium chloride will hinder

525

526

527

528

529

530

531

532

533

534

535

536

537

538

539

540

541

542

543

544

545

546

547

548

549

550

551

552

553

554

555

556 photosynthesis in the experiment. As shown in the Fig. 2, high cell numbers in a bead has a negative effect on photosynthesis. We have found best results can be achieved when the harvested cell numbers are between $250 \times 10^{6}-395 \times 10^{6}$ cells/ $50 \mathrm{~mL}$ falcon tube. Cells inside the beads are oxygen-stressed. Hence it is important to leave air gaps inside the bracelet at each end of the flexible tubing (see Materials and Methods). The same rule applies when performing the experiment in a $5.5 \mathrm{~mL}$ glass vial. It is important to leave air gap of half the volume of the vial.

Results in Fig. 6 showed that prolonged dark exposure of 15 hours has a negative effect on photosynthesis. Algae bead bracelets exposed to 9 hours of darkness (Fig. 6) can be shifted back and forth between dark and light to display color changes over a period of 24-48 hours (the color changes slowly after 24 hours; based on observations in different classrooms, no data was collected). We have also found that once the bracelet is assembled, if it is exposed to light for about 3-4 hours (which we call in our lab as the "light charging of the bracelet") and, then switched to dark for 2-3 hours ["discharging of the bracelet"], the bracelet displays fast color changes as long as the dark exposure time was not exceeded beyond 9 hours (based on observations in different classrooms, no data was collected). But if the assembled bracelet is shifted to dark immediately after assembly, the bracelet fails to display fast color changes. Immobilized oxygen stressed-Chlamydomonas cells in the beads are dependent on photosynthesis for glucose biosynthesis as they are immersed in tap water in the bracelet. Tap water lacks acetate and other nutrients for algal growth. We hypothesize that the initial light exposure allows the cells to synthesize glucose/starch by photosynthesis which is later used to support the high rate of cellular respiration in beads for energy production. If the bracelet is shifted to dark without prior light exposure, the high cellular respiration rate consumes the existing starch in the cells. Hence when this dark-exposed bracelet is exposed to light, the cells will have to synthesize enough glucose/starch via photosynthesis to support the high rate of cellular respiration in the beads and this will take some time. This is reflected in the slow color/pH changes of a bracelet that is exposed to dark immediately after assembly compared to the one that is exposed to light immediately after assembly.

Chlamydomonas can take up exogenous acetate from the TAP medium to make net synthesis of glucose via the Glyoxylate/C2 cycle, which is present in many bacteria, micro-algae and plants (Kunze et al., 2006). Substituting tap water with acetate containing-TAP growth media (heterotrophic and photo-heterotrophic media; Text S2) inside the bracelet will hinder color 
557 change in bracelets/vials as TAP medium has Tris buffer, which has a pKa value of 8.06 at $25^{\circ} \mathrm{C}$

558

559

560

561

562

563

564

565

566

567

568

569

570

571

572

573

574

575

576

577

578

579

580

581

582

583

584

585

586

587

588

589

590

591

592

593

594

595

596

and a buffering range of $\mathrm{pH}$ 7-9. Chlamydomonas grows slower in High Salt (HS) photosynthetic media than in TAP medium as HS medium lacks acetate (Sueoka, 1960). HS medium cannot be used as a substitute for tap water inside the bracelet as we have tried it and have found that the bracelets do not show color changes even if the beads are exposed to light for 48 hours (data not shown).

During spring 2018- fall 2019, the described laboratory activities were incorporated in Biology classes in nine schools and in Biology labs at the University of West Georgia and at the Perimeter College [Georgia State University] (Text S1). To date, we have targeted of about 947 school students in Georgia and hope to target more college students in future. We are proposing a class workflow in Text S3, which is based on the feedback of 12 school teachers and 2 college instructors who participated in the Plant-BLOOME project. Regardless of the suggested time line, instructors can adjust lab times according to their teaching agenda by either spreading the lab activities across multiple classes or by removing one or more activities (Text S3). This will allow the instructor to involve the class in discussion after each activity. Alternatively, students can perform an outdoor experiment by wearing these bracelets/necklaces (you can also make algae bead necklaces) during day time and exposing these bracelets to strong sunlight or wear them in the night to see the water color changes. Conducting the experiment in a $5.5 \mathrm{~mL}$ capped glass vials will expedite the experiment completion within 1.5-2 hours in classrooms. The advantage of performing the experiment in glass vials is that students can clearly monitor oxygen production in photosynthesis by monitoring the buoyancy of the algal beads over time. Bead buoyancy is difficult to clearly visualize in a bracelet because of the narrow diameter of the bracelet tubing.

Photosynthetic efficiencies of Chlamydomonas strains are measured in a laboratory by an oxygen electrode. But many financially disadvantaged schools and institutions of higher learning do not have access to an oxygen electrode. Our hands-on activity can be used to compare crudely photosynthetic efficiencies of Chlamydomonas wild type and photosynthetic mutant strains in a classroom setting. This will allow educators at institutions with limited resources and funding to engage students in critical thinking based on observations of a scientific experiment.

Our lab activities can be customized for different grade levels by adding or removing layers of lab components. Some suggested activities for Middle school, high school and college undergraduates are shown in Table 1, Table 2 and Table 3, respectively. For example, for middle school students the algae bead bracelet or the vial version of the experiment can be used.

Students can observe under light microscopes, swimming Chlamydomonas and its bright orange eyespot which is used by the cell for light sensing and aids photo-taxis [Table 1; Ueki et al., 2016). Photosynthesis is modulated by light color and light intensities (Tymoczko, Berg \& Stryer, 2015). Red and blue light stimulates photosynthesis and other colored light are not utilized for photosynthesis (Tymoczko, Berg \& Stryer, 2015). Hence algae bead bracelets can be used by high school students to test the effects of different light intensities and colored light using different colored light filters (Table 2).

Peer) reviewing PDF | (2020:05:49217:2:0:NEW 27 Jul 2020) 
597 High school students can also conduct a vial experiment with a wild type strain and any available

598

599

600

601

602

603

604

605

606

607

608

609

610

611

612

613

614

\section{Conclusions}

616 Our designed protocol can be used to make beads using motile micro-alga like Chlamydomonas

617

618

619

620

621

622

623

624

625

626

627

628

629

630

\section{1}

632

633

634

635

photosynthetic mutant strain that they have access to. Photosynthetic mutants like the cytochrome $f$ deficient mutant ( $\triangle p e t A$ ) [CC-3737 petA (N153Q)]; the D1-less mutant (Fud7) [ CC-4147 FUD7 (psbA deletion) $\mathrm{mt}+$ ] and the D2-less mutant ( $\triangle P s b D$ ) [CC-4385 PsbD (deletion) $\mathrm{mt}+$ are available via Chlamydomonas Resource Center (Table 2). 10E35 mutant can be obtained from our lab. Additionally, a basic bioinformatic laboratory can be added to the high school Biology lab. The DNA sequence of the mutated gene in the photosynthetic Chlamydomonas mutant can be given to students and they can use the DNA sequence to BLAST the NCBI database to identify the gene and the protein. Students can also check for paralogs/orthologs of the identified gene/protein (Table 2). For college undergraduate level Biology labs, additional molecular and biochemical layers can be added on top of the high school lab components as shown in Table 3.

We have provided class work-flow, sample pre- and post-lab questions and a rubric for grading pre- and post-lab assignments which can be used by educators (Text S3). The assignments and the rubric can be customized according to the knowledge base of students in the class. In summary, science literacy in young students can be improved by studying a "pond-scum" which is used by plant biologists, neuroscientists, biomedical and renewable energy researchers and can show them the inter-disciplinary nature of $21^{\text {st }}$ century Biology.

reinhardtii. These algal beads can be used for basic photosynthesis labs or for comparative studies of relative rates of photosynthesis and cellular respiration in Chlamydomonas wild type and mutant strains. Although our work was performed with the objective of designing engaging hands-on plant biology labs for K16 Biology students, it might be useful to bioenergy researchers who are interested in exploring the use of immobilized Chlamydomonas or other motile green algae for biofuel production (Scranton et al., 2015; Radakovits et al., 2010; Canbay, Kose \& Oncel, 2018). Our lab activities using the wild type Chlamydomonas strain can be performed both in glass vials and in bracelets. Based on our class room experiences at nine schools and two colleges in Georgia and the enthusiasm of the plant community members at the educational booths at the Plant Biology meetings organized by ASPB, we envision that young students will find the "bracelet" approach more enjoyable than conducting the same experiment in glass vials (Text S1). Our lab activities are inexpensive and can been customized according to grade levels.

\section{Acknowledgements}

The authors would like to thank Dr. Krishna K. Niyogi (Professor, Department of Plant and Microbial Biology, UC Berkeley, CA) for providing us with the Chlamydomonas wild type strain $4 \mathrm{~A}+$. We would also like to thank the following science teachers and instructors who allowed us to implement our lab activities in their classrooms at their institutions: Dagmah

Peer) reviewing PDF | (2020:05:49217:2:0:NEW 27 Jul 2020) 
636 Alexander and Dione Belser (Camp Creek Middle School, GA), Gini Loeffler (East Coweta 637 Middle School, GA),Tim Hawig (Carrollton High School, GA), Chrissy Loveless (Carrollton 638 Junior High School, GA), Darrius Shaw (Crabapple Middle School, GA), Patricia Thrower 639 (Bremen Middle School, GA), Kallendra Mathews (Bremen High School, GA), Keisha Barnes 640 (Lithia Springs High School, GA), Gina Watkiss (The Heritage School, GA), Emily Camp (The 641 Heritage School, GA), Karin van den Hoonaard (The Heritage School, GA), Ryan Danbury (The 642 Heritage School, GA) and Phillip Grovenstein (Lab Coordinator and Instructor, Perimeter 643 College, Life \& Earth Sciences, Georgia State University, GA). We are grateful to Mr. Taylor 644 Box (Biology major, University of West Georgia, GA), Miss Victoria Johnson (Elementary 645 school student, Jones Elementary School, GA) and Dr. Melissa Johnson (Associate Professor in 646 Biology, University of West Georgia, GA and mother of Miss Victoria Johnson) for their 647 participation in the Chlamydomonas bracelet making demonstration videos.

648

\section{References}

650 Algae Immobilised in Alginate balls. 2016. Studies of photosynthesis and respiration | Gene

651 Technology Access Centre. Available at https://www.gtac.edu.au/wp-

652 content/uploads/2016/01/Algae AlginateBalls LabPreparation.pdf(accessed May 19, 2020).

653 Canbay E, Kose A, Oncel SS. 2018. Photobiological hydrogen production via immobilization:

654 understanding the nature of the immobilization and investigation on various conventional

655 photobioreactors. 3 Biotech 8:244. DOI: https://doi.org/10.1007/s13205-018-1266-3

656 Carolina Quicktips Making Algae Beads | Carolina Biological. Available at

657 https://www.carolina.com/pdf/activities-articles/carolina-qt-making-algae-beads-

658 cb814921806.pdf accessed July $3^{\text {rd }}, 2020$ ).

659 Critical tool for brain research derived from "pond scum"| NSF - National Science Foundation.

660 2013. Available at https://www.nsf.gov/discoveries/disc_summ.jsp? cntn id $=129298$ (accessed

661 May 19, 2020).

662 Gotovtsev PM, Yuzbasheva EY, Gorin K V., Butylin V V., Badranova GU, Perkovskaya NI, 663 Mostova EB, Namsaraev ZB, Rudneva NI, Komova A V., Vasilov RG, Sineokii SP. 2015.

664 Immobilization of microbial cells for biotechnological production: Modern solutions and 665 promising technologies. Applied Biochemistry and Microbiology 51:792-803. DOI:

$66610.1134 / \mathrm{S} 0003683815080025$.

667 Kröger M, Müller-Langer F. 2012. Review on possible algal-biofuel production processes, 668 Biofuels 3:333-349. DOI: 10.4155/bfs.12.14.

669 Kunze M, Pracharoenwattana I, Smith SM, Hartig A. 2006. A central role for the peroxisomal 670 membrane in glyoxylate cycle function. Biochimica et Biophysica Acta - Molecular Cell

671 Research 1763:1441-1452. DOI: 10.1016/j.bbamcr.2006.09.009.

672 Merchant SS, Prochnik SE, Vallon O, Harris EH, Karpowicz SJ, Witman GB, Terry A, Salamov 
673 A, Fritz-Laylin LK, Maréchal-Drouard L, Marshall WF, Qu LH, Nelson DR, Sanderfoot AA, 674 Spalding MH, Kapitonov V V., Ren Q, Ferris P, Lindquist E, Shapiro H, Lucas SM, Grimwood 675 J, Schmutz J, Grigoriev I V., Rokhsar DS, Grossman AR, Cardol P, Cerutti H, Chanfreau G, 676 Chen CL, Cognat V, Croft MT, Dent R, Dutcher S, Fernández E, Fukuzawa H, González677 Ballester D, González-Halphen D, Hallmann A, Hanikenne M, Hippler M, Inwood W, Jabbari K, 678 Kalanon M, Kuras R, Lefebvre PA, Lemaire SD, Lobanov A V., Lohr M, Manuell A, Meier I, 679 Mets L, Mittag M, Mittelmeier T, Moroney J V., Moseley J, Napoli C, Nedelcu AM, Niyogi K, 680 Novoselov S V., Paulsen IT, Pazour G, Purton S, Ral JP, Riaño-Pachón DM, Riekhof W, 681 Rymarquis L, Schroda M, Stern D, Umen J, Willows R, Wilson N, Zimmer SL, Allmer J, Balk J, 682 Bisova K, Chen CJ, Elias M, Gendler K, Hauser C, Lamb MR, Ledford H, Long JC, Minagawa 683 J, Page MD, Pan J, Pootakham W, Roje S, Rose A, Stahlberg E, Terauchi AM, Yang P, Ball S, 684 Bowler C, Dieckmann CL, Gladyshev VN, Green P, Jorgensen R, Mayfield S, Mueller-Roeber

685

686

687

688

689

690

691

692

693

694

695

696

697

698

699

700

701

702

703

704

705

706

707

708

709 B, Rajamani S, Sayre RT, Brokstein P, Dubchak I, Goodstein D, Hornick L, Huang YW, Jhaveri J, Luo Y, Martínez D, Ngau WCA, Otillar B, Poliakov A, Porter A, Szajkowski L, Werner G, Zhou K. 2007. The Chlamydomonas genome reveals the evolution of key animal and plant functions. Science 318:245-251. DOI: 10.1126/science.1143609.

Nguyen K, Swint J, Page J, Kim K, Smith K, Truong T and Swilley K. 2017. Identification of a Novel Gene That Plays a Role in High Light Tolerance in the Green Micro-alga Chlamydomonas reinhardtii. Proceedings of the National Conference of Undergraduate Research, 407-417.

http://www.ncurproceedings.org/ojs/index.php/NCUR2017/article/view/2292

Photosynthesis and Cellular Respiration Kit for General Biology Instructor's Guide | Bio-Rad. Available at $h t t p s: / / w w w . b i o-r a d . c o m / w e b r o o t / w e b / p d f / l s e / l i t e r a t u r e / 10000086257 . p d f$ (accessed July $1^{\text {st }}$, 2020).

Radakovits R, Jinkerson RE, Darzins A, Posewitz MC. 2010. Genetic engineering of algae for enhanced biofuel production. Eukaryotic Cell 9:486-501. DOI: 10.1128/EC.00364-09.

Resources For Teaching - Chlamydomonas Resource Center. Available at https://www.chlamycollection.org/resources/resources-for-teaching/ (accessed May 19, 2020).

Scranton MA, Ostrand JT, Fields FJ, Mayfield SP. 2015. Chlamydomonas as a model for biofuels and bio-products production. Plant Journal 82:523-531. DOI: 10.1111/tpj.12780.

Silflow CD, Lefebvre PA. 2001. Assembly and motility of eukaryotic cilia and flagella. Lessons from Chlamydomonas reinhardtii. Plant Physiology 127:1500-1507. DOI: 10.1104/pp.010807.

Sueoka N. 1960. Mitotic Replication Of Deoxyribonucleic Acid In Chlamydomonas reinhardtii. Proceedings of the National Academy of Sciences of the United States of America 46: 8391.DOI: $10.1073 /$ pnas.46.1.83.

The 12 Principles of Plant Biology|American Society of Plant Biologists. Available at https://aspb.org/education-outreach/k12-roots-and-shoots/the-12-principles-of-plant-biology2/\#toggle-id-1 (accessed May 19, 2020). 
710 The Lab Depot | What is Pure Water? Available at https://www. Labdepotinc.com/articles/pure-

711 water-information.html\# (accessed May 19, 2020).

712 Tymoczko JL, Berg JM, Stryer L. 2015. Biochemistry: A Short Course. Third edition. New

713 York: W.H. Freeman \& Company.

714 Ueki N, Ide T, Mochiji S, Kobayashi Y, Tokutsu R, Ohnishi N, Yamaguchi K, Shigenobu S, 715 Tanaka K, Minagawa J, Hisabori T, Hirono M, Wakabayashi KI. 2016. Eyespot-dependent

716 determination of the phototactic sign in Chlamydomonas reinhardtii. Proceedings of the

717 National Academy of Sciences of the United States of America 113:5299-5304. DOI:

718 10.1073/pnas.1525538113.

719 Whitehead P. 2020. Dissolved Gases in Purified Water | ELGA LabWater. Available at 720 https://www.elgalabwater.com/blog/dissolved-gases-purified-water (accessed May 19, 2020).

721 Zhang S. 2015. A Cure for Blindness Just Might Come From Algae | WIRED. Available at 722 https://www.wired.com/2015/09/cure-blindness-just-might-come-algae/ (accessed May 19, 723 2020). 


\section{Figure 1}

Photosynthesis and cellular respiration-induced $\mathrm{pH} /$ color changes in vials containing Chlamydomonas $4 \mathrm{~A}+$ strain beads in de-ionized water and tap water.

C stands for control vials which do not contain algae beads and E stands for experimental vials containing algae beads. (A) Color changes in de-ionized water. (B) Color changes in tap water. Vials were exposed to light and darkness for 2 hours. Algal beads had approximately 2 X $10^{6}$ cells/beads and 8 algal beads were used per experimental vial. All statistical analyses can be found in https://doi.org/10.6084/m9.figshare.12344024.v1, Data S1, Data S2 and Table S1.
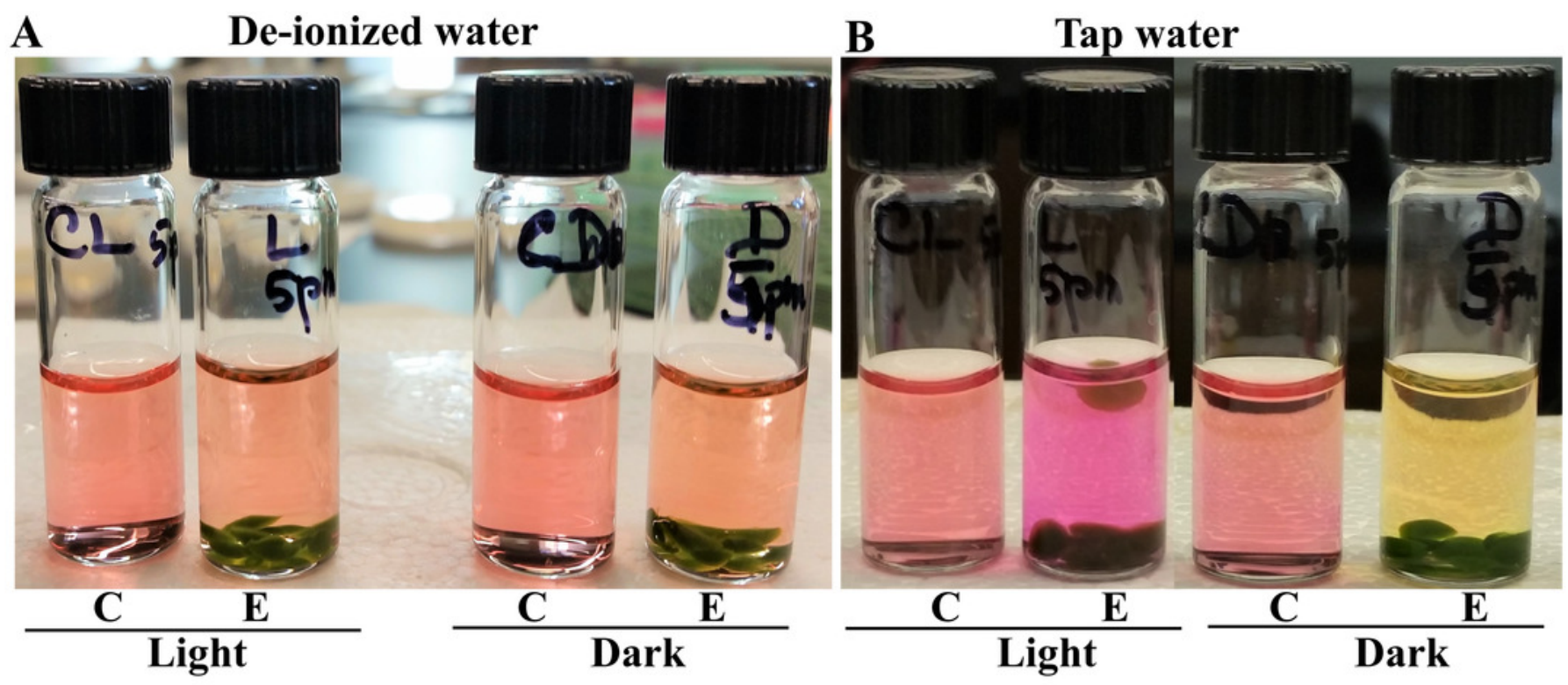


\section{Figure 2}

Effect of cell numbers per Chlamydomonas $4 \mathrm{~A}+$ strain bead on photosynthesis and cellular respiration-induced $\mathrm{pH} /$ color changes in tap water.

" $C$ " stands for control vials that do not contain algae beads. " $E$ " stands for experimental vials containing algae beads. (A) Color changes in experimental vials that contained beads which had approximately $4 \times 10^{6}$ cells/bead. (B) Color changes in experimental vials that contained beads which had approximately $2 \times 10^{6}$ cells/bead. Light and dark exposure of vials was for 2 hours. 8 algal beads were used per experimental vial. All statistical analyses can be found in https://doi.org/10.6084/m9.figshare.12344024.v1 , Data S1, Data S2 and Table S2. 

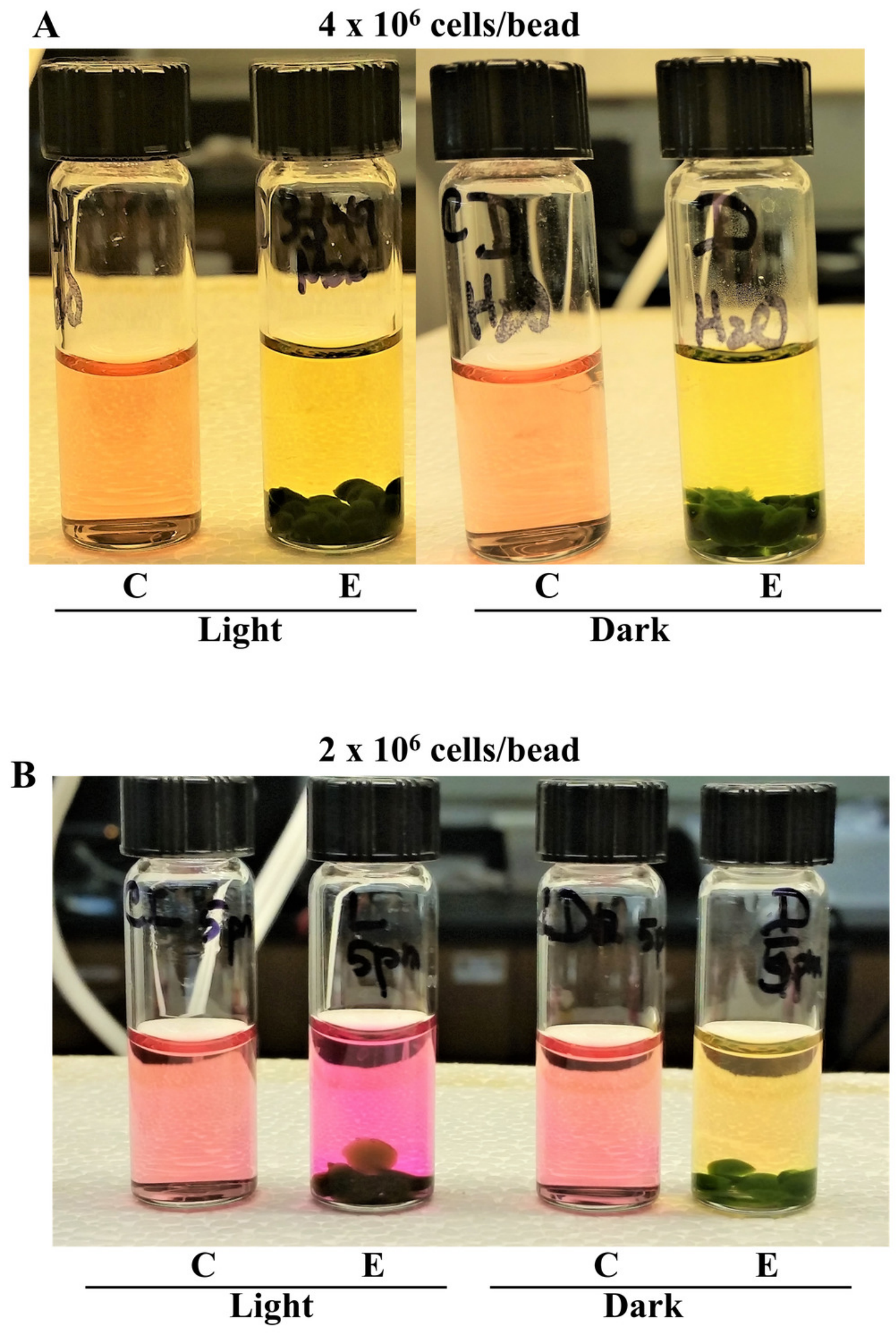


\section{Figure 3}

Indirect monitoring of carbon dioxide percentage inside the 4A+ bead bracelet under constant light and darkness using bicarbonate indicator.

(A) Control algal bracelet that has not been exposed to light or to darkness (zero time point).

(B) An algal bracelet that was exposed to darkness for 3 hours. (C) An algal bracelet that was exposed to light for 3 hours. Water color change was monitored in dark and light. Algal beads had approximately $2 \times 10^{6}$ cells/bead. Number of algal beads in the control, dark- and lightexposed bracelets were 32,38 and 38 , respectively. All statistical analyses can be found in https://doi.org/10.6084/m9.figshare.12344024.v1 , Data S1, Data S2 and Table S3.

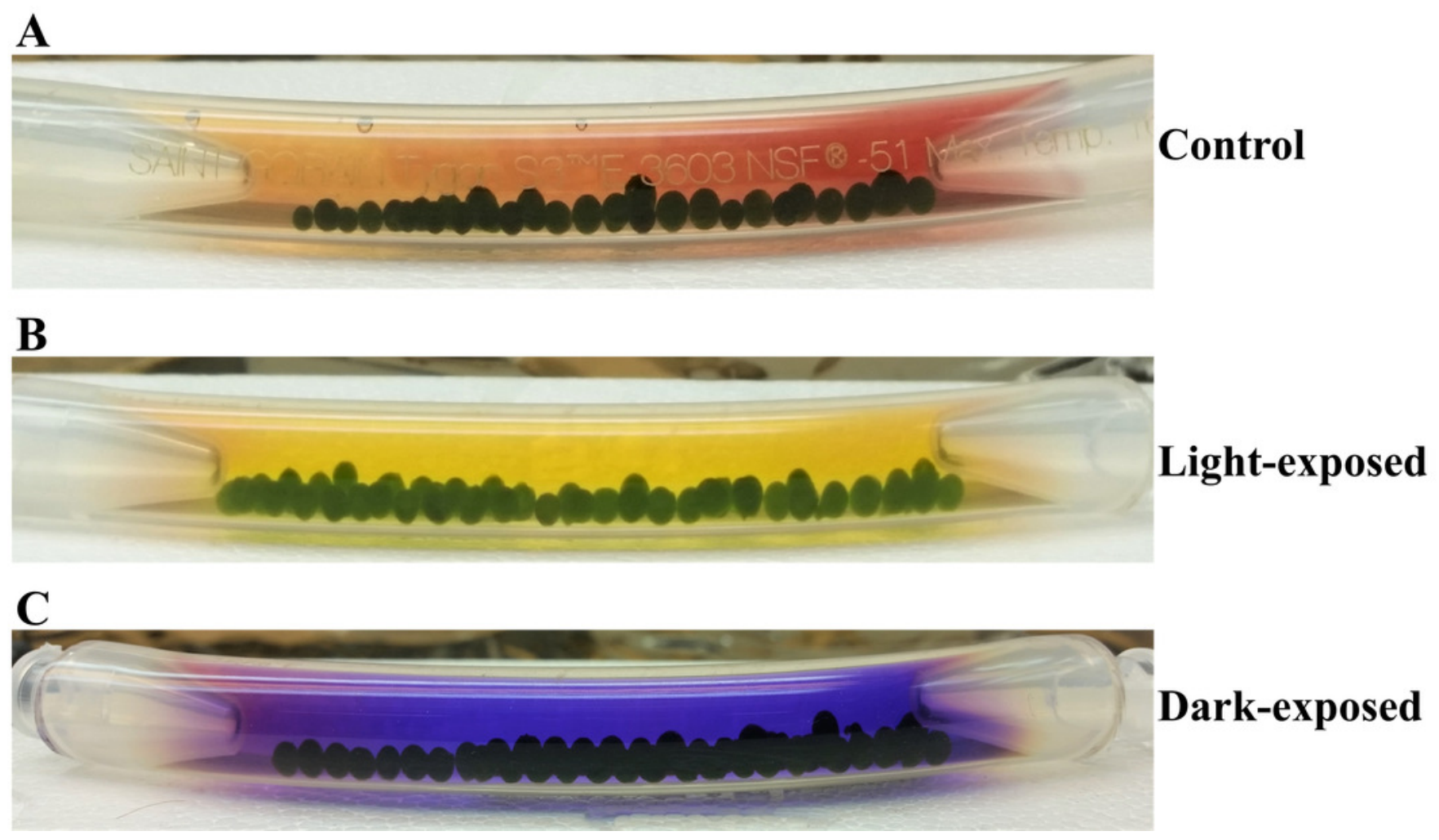




\section{Figure 4}

Time course monitoring of photosynthesis-induced color/pH changes in the darkadapted $4 \mathrm{~A}+$ bead bracelet when shifted to light.

(A) An algal bracelet that was dark adapted for 4 hours. (B) Dark-adapted bracelet exposed to light for 1 hour. (C) Dark-adapted bracelet exposed to light for 2 hours. (D) Dark-adapted bracelet exposed to light for 3 hours. (E) Dark-adapted bracelet exposed to light for 4 hours. Algal beads have approximately $2 \times 10^{6}$ cells/bead. Number of algal beads in the bracelet was 15. Bicarbonate indicator was used as a $\mathrm{pH}$ indicator. 


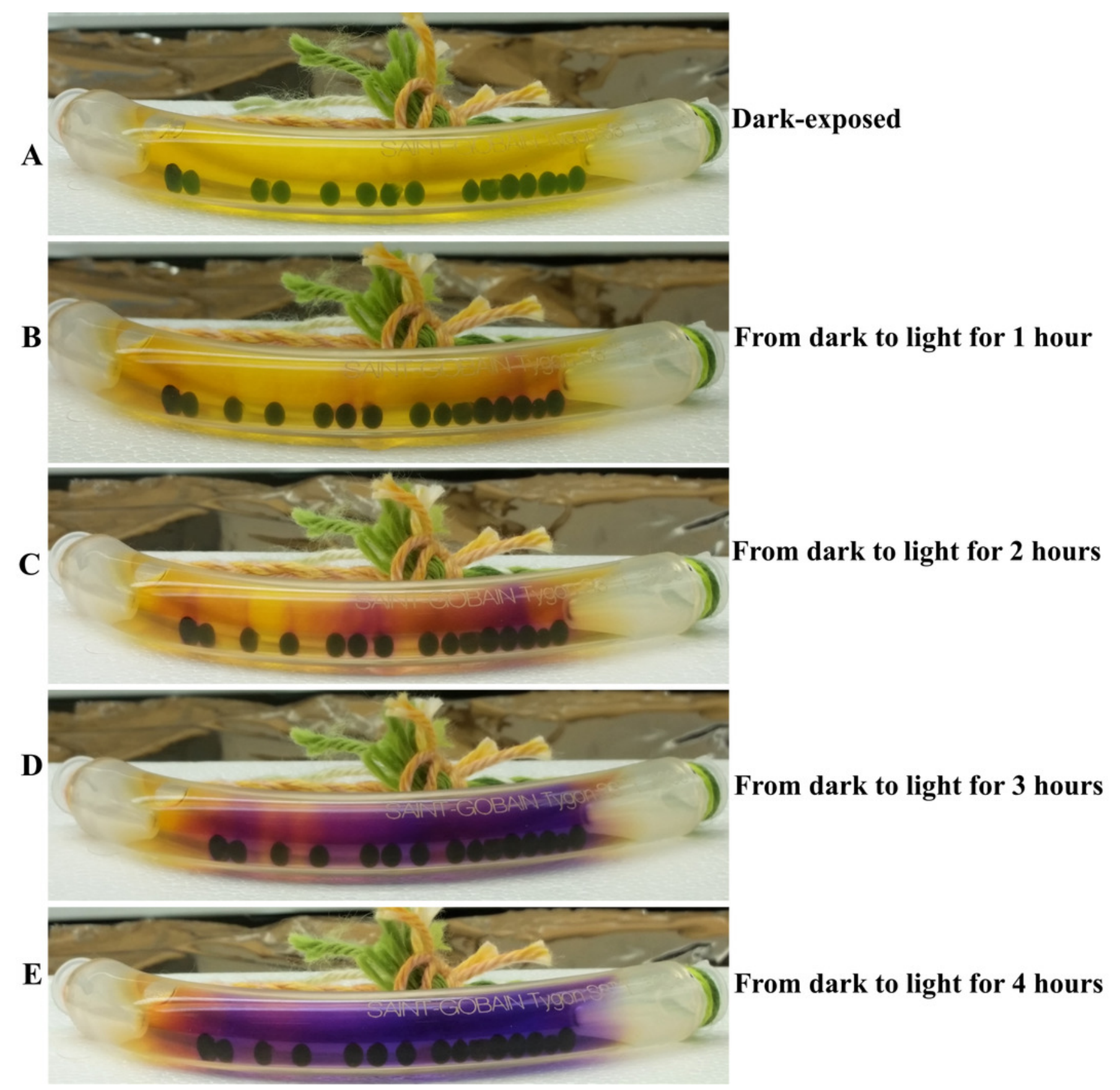




\section{Figure 5}

Time course monitoring of cellular respiration-induced color/pH changes in the lightadapted $4 A+$ bead bracelet when shifted to darkness.

A) An algal bracelet that was light adapted for 4 hours. (B) Light-adapted bracelet exposed to dark for 1 hour. (C) Light-adapted bracelet exposed to dark for 2 hours. (D) Light-adapted bracelet exposed to dark for 3 hours. Algal beads had approximately $2 \times 10^{6}$ cells $/$ bead. The bracelet contained thirty-six $4 \mathrm{~A}+$ strain beads. Bicarbonate indicator was used as a $\mathrm{pH}$ indicator.

A

B

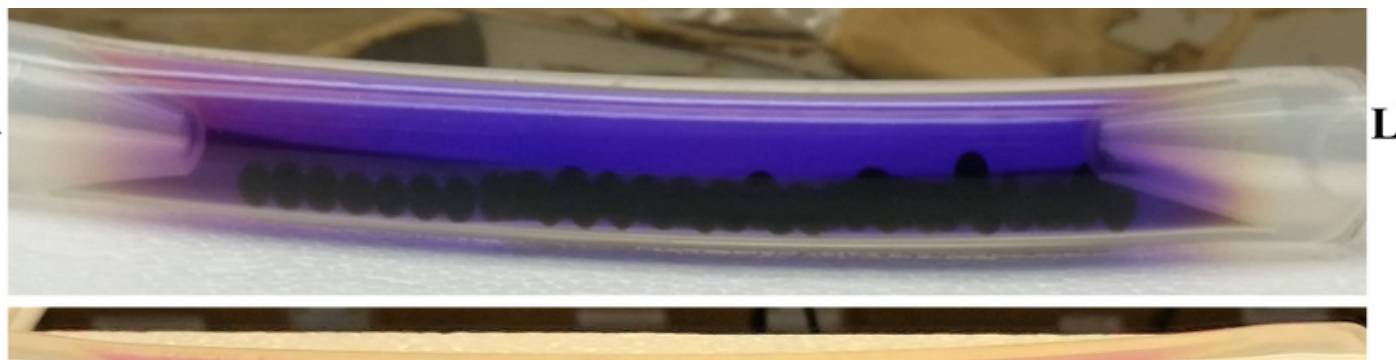

C

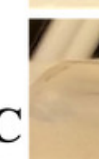

D
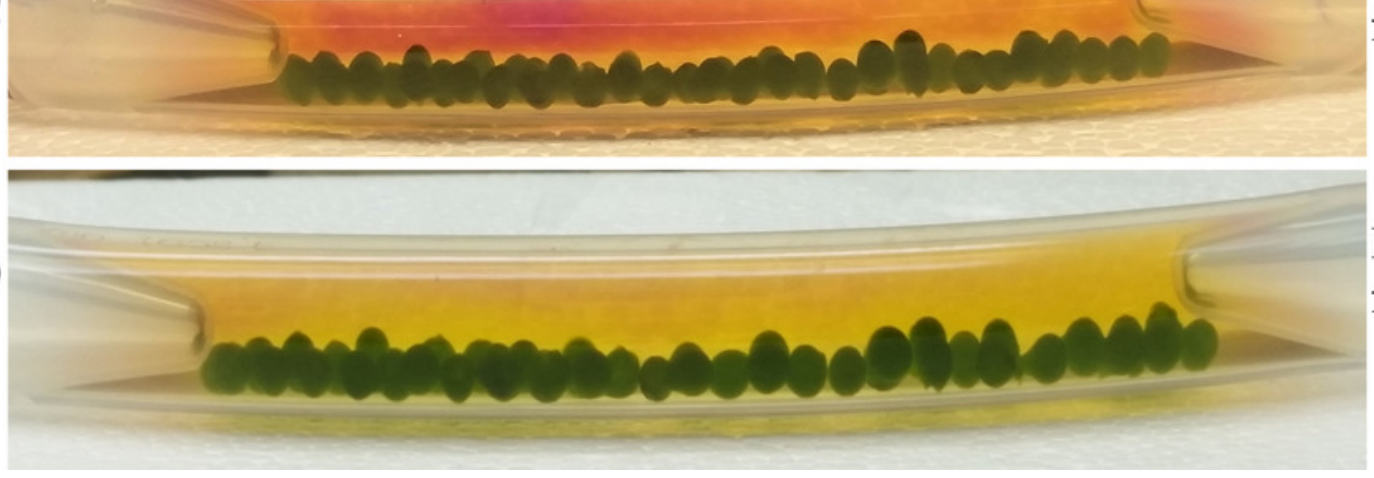

Light-exposed

From light to dark for 1 hour

From light to dark for 2 hours

From light to dark for 3 hours 


\section{Figure 6}

Effect of prior dark exposure duration on photosynthesis-induced color/pH changes in $4 \mathrm{~A}+$ bead bracelet in light.

(A) An algal bracelet that was dark adapted for 9 hours. (B) 9 hours-dark adapted-bracelet shifted to light for 4 hours. (C) An algal bracelet that was dark adapted for 15 hours. (D)15 hours-dark adapted-bracelet shifted to light for 12 hours. Algal beads had approximately $2 \mathrm{X}$ $10^{6}$ cells/bead. Both bracelets contained 38 beads. All statistical analyses can be found in https://doi.org/10.6084/m9.figshare.12344024.v1 , Data S1, Data S2 and Table S4.

A

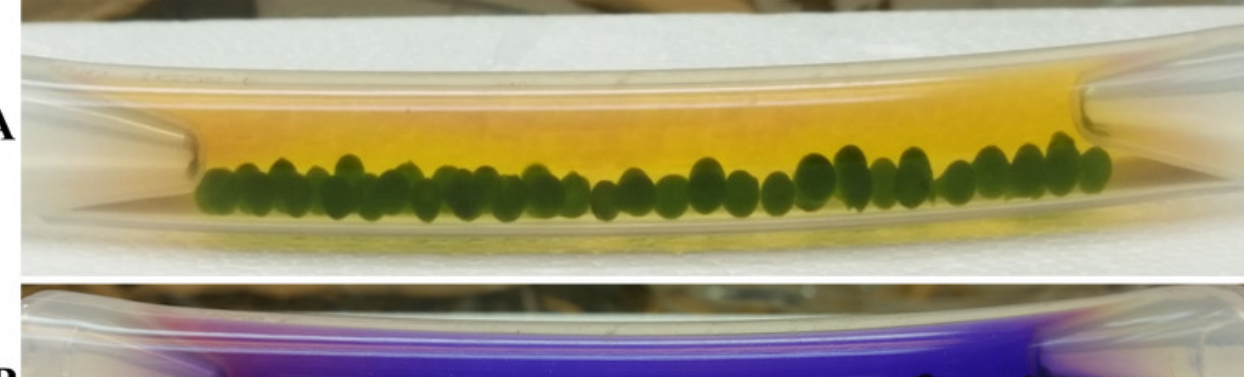

B

C

D

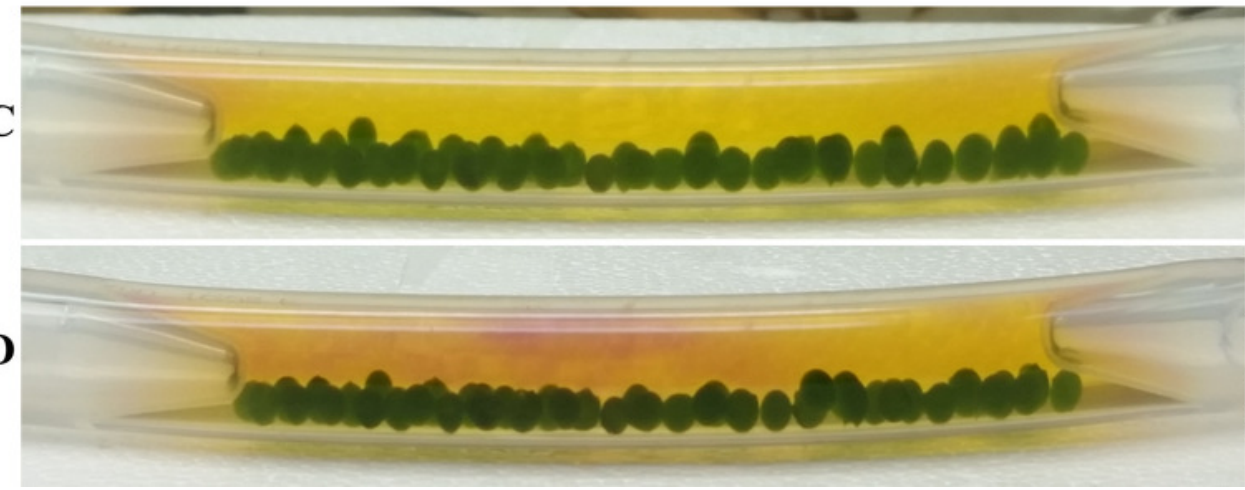

Dark-exposed for 9 hours

From 9 hours in darkness to light for 4 hours

Dark-exposed for 15 hours

From 15 hours in darkness to light for 12 hours 


\section{Figure 7}

Comparative studies of photosynthesis and cellular respiration-induced $\mathrm{pH} /$ color changes in wild type $4 \mathrm{~A}+$ and 10E35 bead vials under light and darkness.

(A) Control, 10E35 and 4A+ bead vials before light exposure. (B) Control, 10E35 and 4A+ bead vials after 30 minutes of light exposure. (C) Control, 10E35 and 4A+ bead vials after 1 hour of light exposure. (D) Control, 10E35 and 4A+ bead vials before dark exposure. (E) Control, 10E35 and 4A+ bead vials after 30 minutes of dark exposure. (F) Control, $10 E 35$ and $4 \mathrm{~A}+$ bead vials after 1 hour of dark exposure. Algal beads of each strain had approximately 2 $X 10^{6}$ cells/bead. Eight beads of each strain were used per experimental vial for the experiment. The order of the vials from left to right: control, 10E35 and 4A+ vials. All statistical analyses can be found in https://doi.org/10.6084/m9.figshare.12344024.v1, Data S1, Data S2 and Table S5. 
Light set

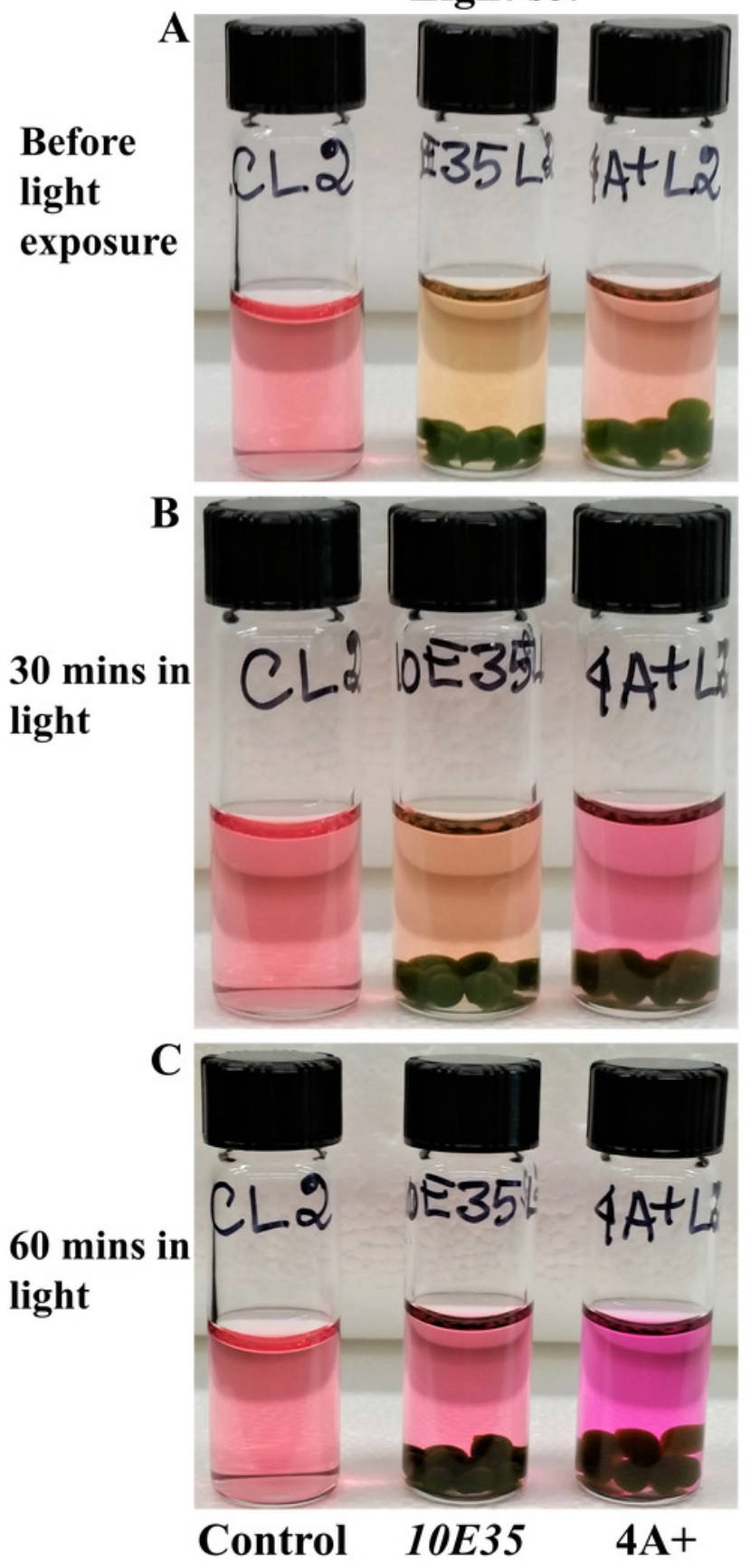

Dark set

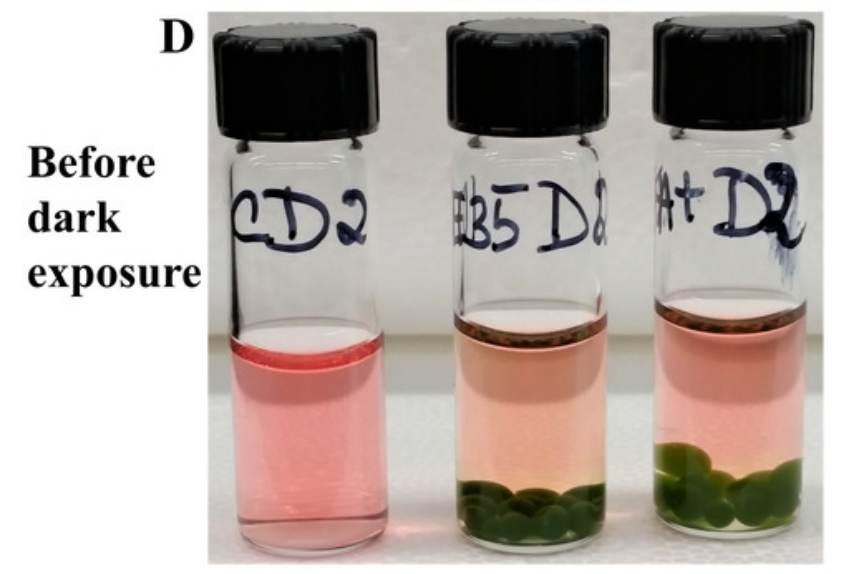

30 mins in dark

E
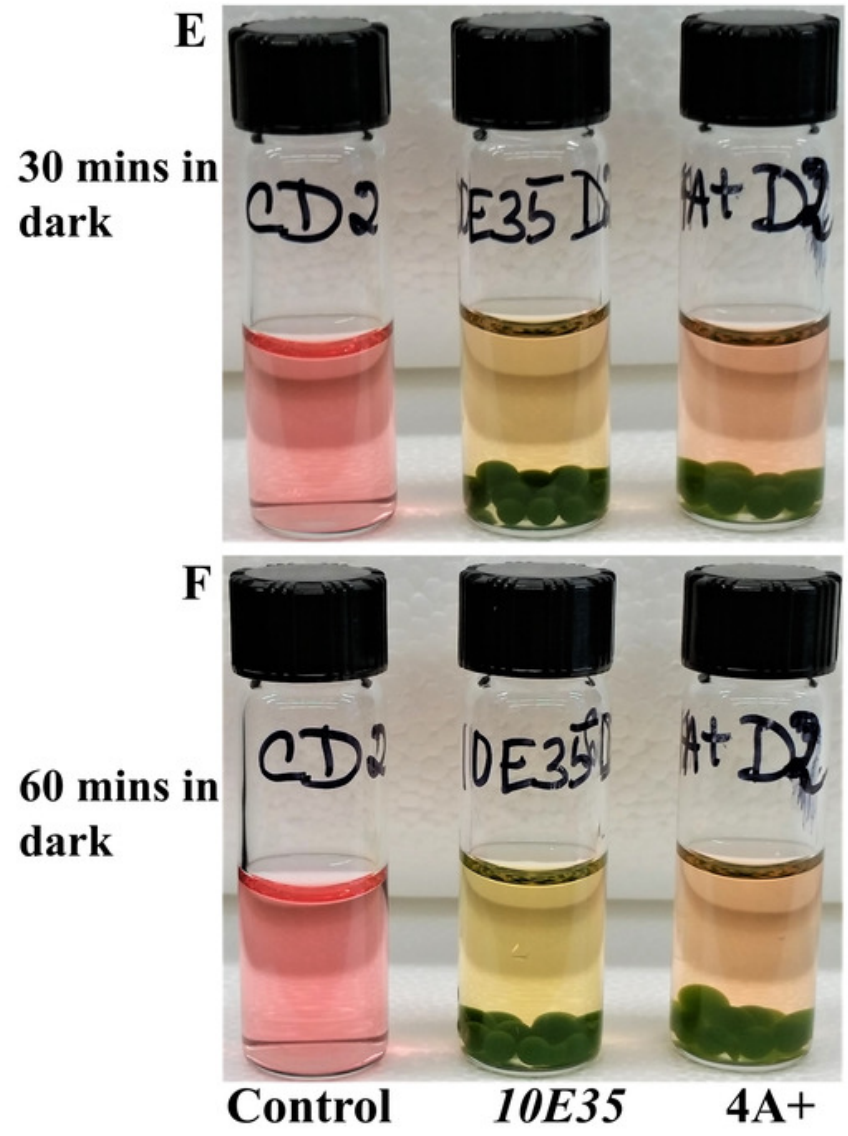


\section{Figure 8}

Time course monitoring of cellular respiration-induced color/pH changes in the dark in $4 \mathrm{~A}+$ and 10E35 bead vials that were adapted to light for 4 hours.

These vials are the light-adapted vials from the Fig. 7 experiments. (A) Light-adapted control, $10 E 35$ and $4 \mathrm{~A}+$ bead vials before dark exposure. (B) Control, 10E35 and 4A+ bead vials after 15 minutes of dark exposure. (C) Control, 10E35 and 4A+ bead vials after 30 minutes of dark exposure. (D) Control, 10E35 and $4 A+$ bead vials after 45 minutes of dark exposure. (E) Control, 10E35 and 4A+ bead vials after 1 hour of dark exposure. The order of the vials from left to right: control, 10E35 and 4A+ vials. All statistical analyses can be found in https://doi.org/10.6084/m9.figshare.12344024.v1 , Data S1, Data S2 and Table S6. 


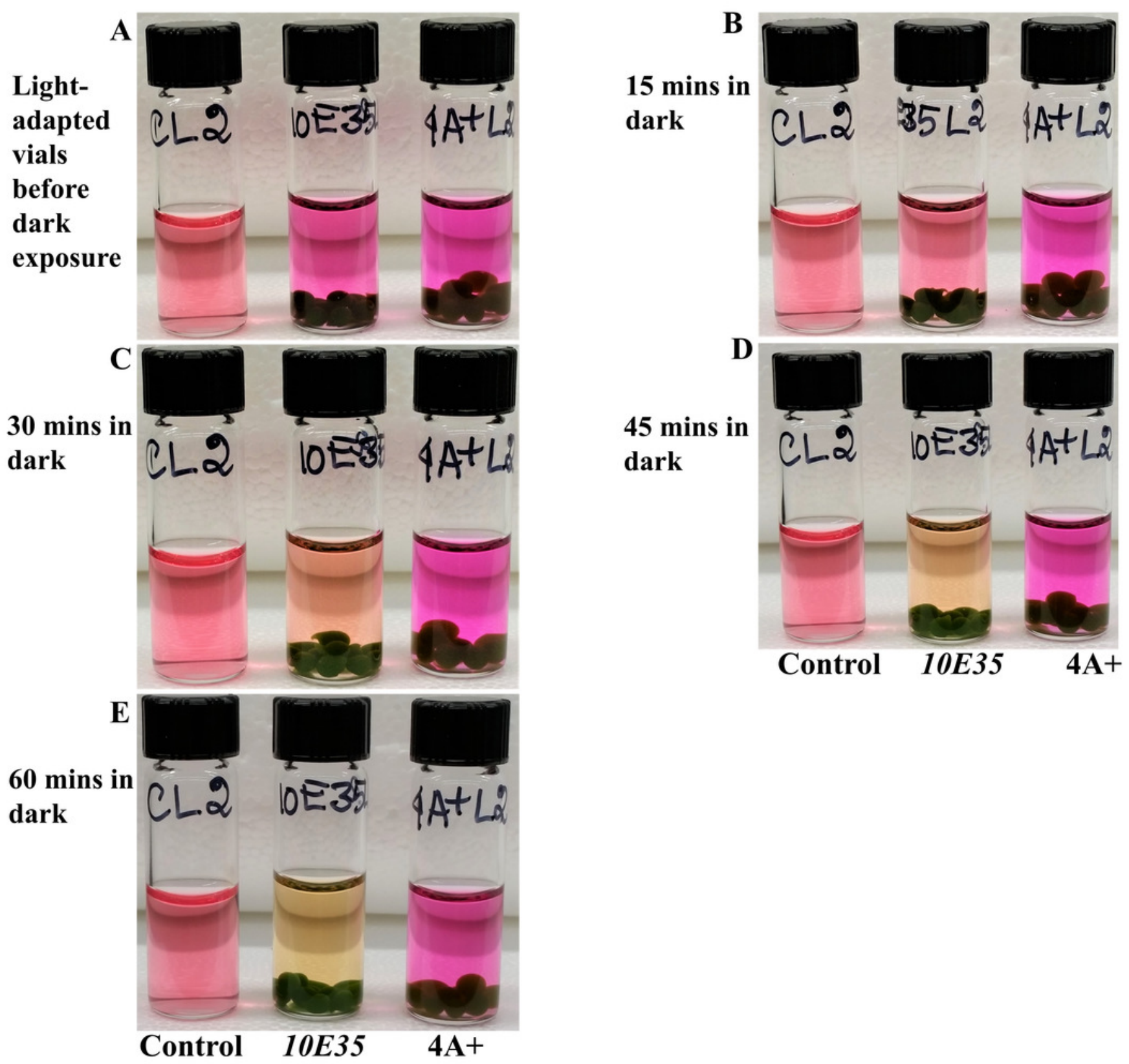




\section{Figure 9}

Time course monitoring of photosynthesis-induced color/pH changes in the light in $4 \mathrm{~A}+$ and $10 E 35$ bead vials that were adapted to darkness for 6 hours.

These vials are the dark-adapted vials from the Fig. 8 experiments. (A) Dark-adapted control, $10 E 35$ and $4 \mathrm{~A}+$ bead vials before light exposure. (B) Control, 10E35 and $4 \mathrm{~A}+$ bead vials after 30 minutes of light exposure. (C) Control, 10E35 and 4A+ bead vials after 1 hour of light exposure. (D) Control, 10E35 and $4 \mathrm{~A}+$ bead vials after 2 hours of light exposure. (E) Control, $10 E 35$ and $4 A+$ bead vials after 3 hours of light exposure. (F) Control, 10E35 and 4A+ bead vials after 48 hours of light exposure. The order of the vials from left to right: control, 10E35 and $4 A+$ vials. All statistical analyses can be found in https://doi.org/10.6084/m9.figshare.12344024.v1 , Data S1, Data S2 and Table S7. 
Dark-

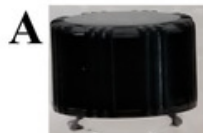
adapted vials before light exposure

C

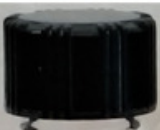

1 hour in

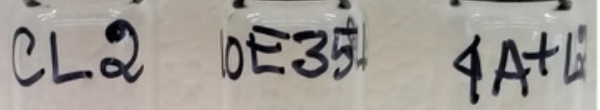
light
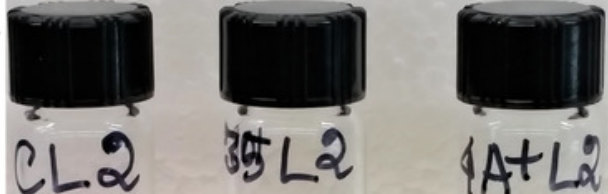

35 L 2
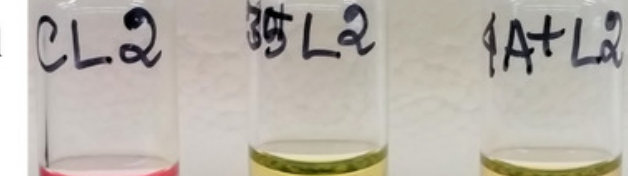

e
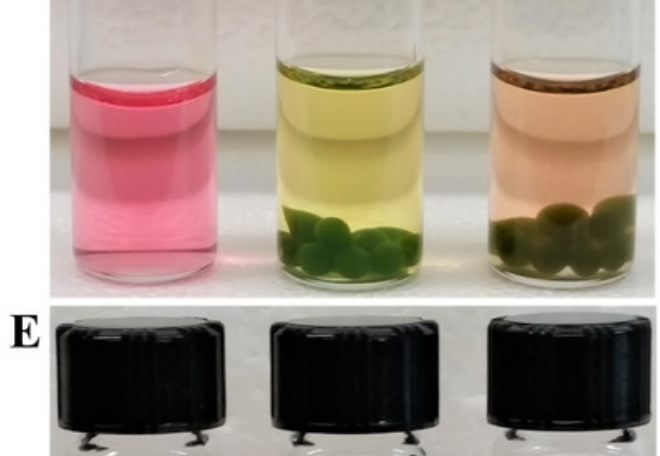

3 hours in 2

light
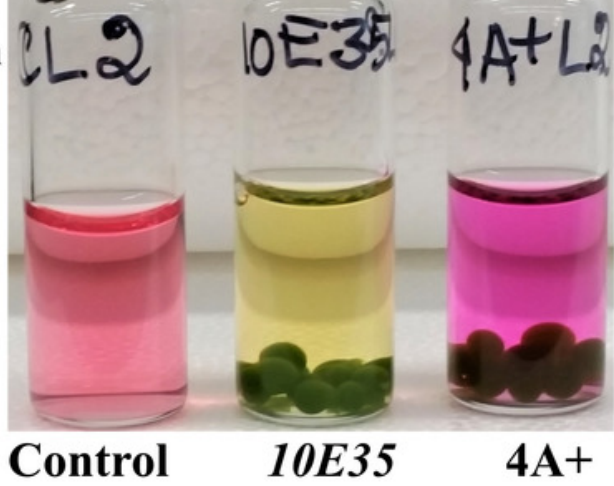

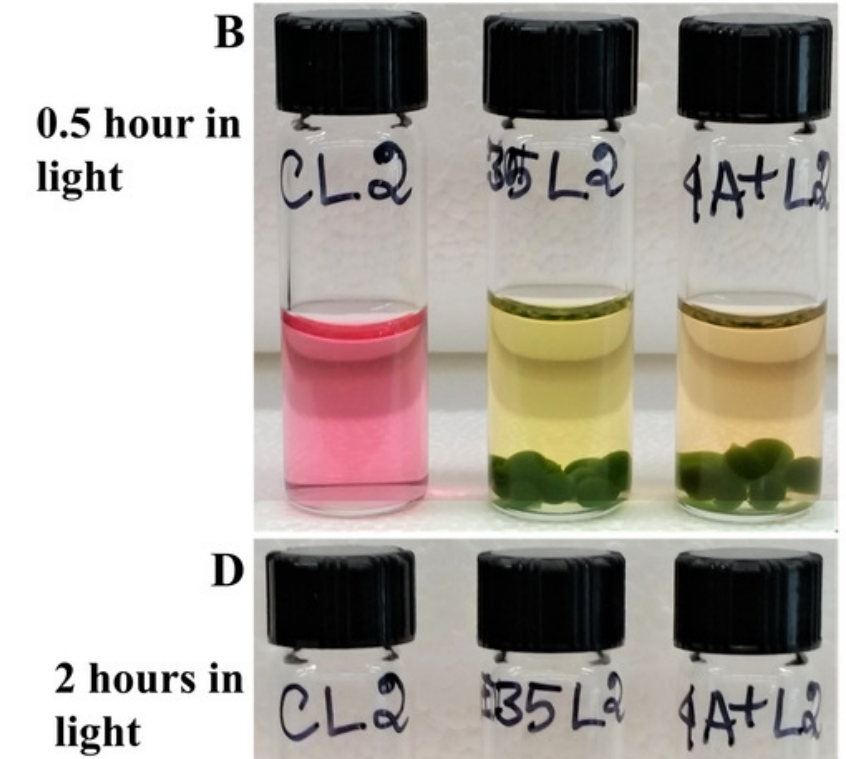

48 hours in

light
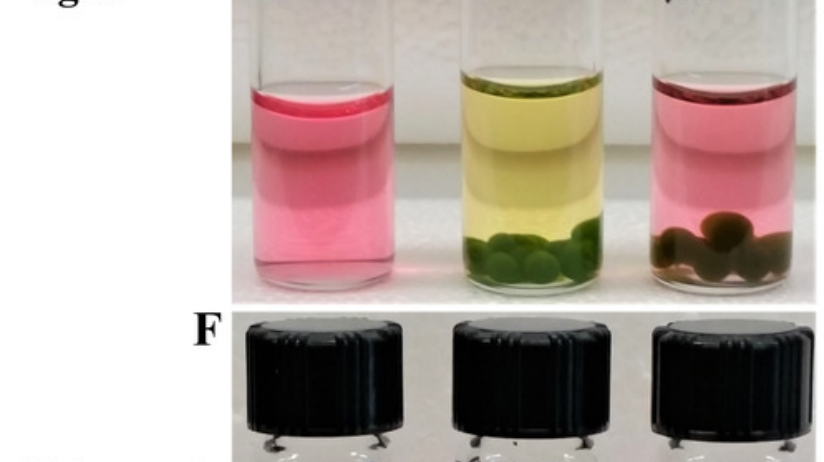

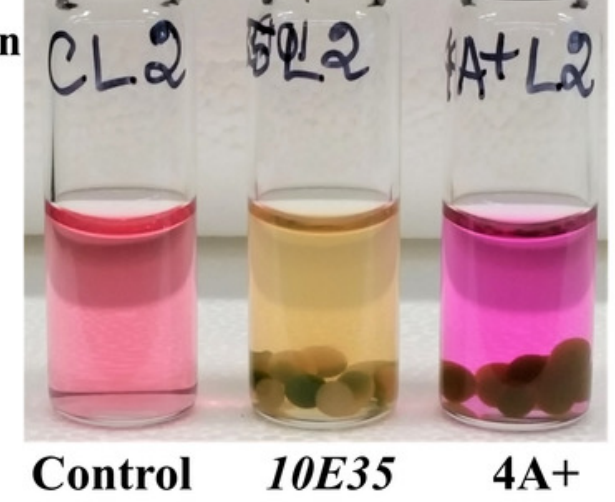




\section{Table 1 (on next page)}

Customization of the photosynthesis lab for middle school students. 


\begin{tabular}{|l|l|}
\hline \multicolumn{1}{|c|}{ Activities } & \multicolumn{1}{|c|}{ Comments } \\
\hline $\begin{array}{l}\text { 1. Observation of swimming Chlamydomonas } \\
\text { cells under bright light microscope }\end{array}$ & $\begin{array}{l}\text { Students can observe the orange eye spot that } \\
\text { functions like "human eye" and helps in } \\
\text { photo-taxis. Orange color of eyespot is due to } \\
\text { carotenoids. }\end{array}$ \\
\hline $\begin{array}{l}\text { 2. Chlamydomonas photosynthetic pigment } \\
\text { analyses by paper chromatography }\end{array}$ & $\begin{array}{l}\text { Pigments can be extracted by teachers using } \\
100 \% \text { acetone from pigment-deficient } \\
\text { photosynthetic strains and wild type strains. } \\
\text { Spinach extract and cyanobacterial } \\
\text { Phycocyanin powder (Fisher Scientific) can } \\
\text { be used in the paper chromatography } \\
\text { experiment to compare pigments in } \\
\text { phylogenetically separated species. } \\
\text { Chromatography lab can be also connected } \\
\text { with fall leaf color change biochemistry and } \\
\text { carotenoids. }\end{array}$ \\
\hline $\begin{array}{l}\text { 3. Students can observe the red fluorescence } \\
\text { of Phycocyanin solution under cell phone } \\
\text { LED light }\end{array}$ & $\begin{array}{l}\text { Students will learn the oceans can change in } \\
\text { color in summer and winter because of } \\
\text { cyanobacterial bloom concentration and will } \\
\text { know about cyanobacterial pigments: } \\
\text { cyanobacterial pigments, phycocyanin and } \\
\text { phycoerythrin. }\end{array}$ \\
\hline $\begin{array}{l}\text { 4. Photo-taxis lab using Chlamydomonas wild } \\
\text { type strain and the lts } 1-211 \text { mutant (Ukei et } \\
\text { al. 2016) }\end{array}$ & $\begin{array}{l}\text { levoid of carotenoids that shows reverse } \\
\text { phototactic behavior compared to the wild } \\
\text { type strain in the light. Students can point a } \\
\text { flash light to culture plates of the two strains } \\
\text { and observe the phototaxis pattern of the two } \\
\text { strains. lts } 1-211 \text { moves towards light while } \\
\text { the wild type strain moves away from the } \\
\text { light. }\end{array}$ \\
\hline As described in this manuscript \\
\hline
\end{tabular}


Table 2 (on next page)

Customization of the photosynthesis lab for high school students. 


\begin{tabular}{|c|c|}
\hline Activities & Comments \\
\hline $\begin{array}{l}\text { 1. Observation of swimming Chlamydomonas } \\
\text { cells under bright light microscope }\end{array}$ & $\begin{array}{l}\text { Students can observe the orange eye spot that } \\
\text { functions like "human eye" and helps in } \\
\text { photo-taxis. Orange color of eyespot is due to } \\
\text { carotenoids. }\end{array}$ \\
\hline $\begin{array}{l}\text { 2. Chlamydomonas photosynthetic pigment } \\
\text { analyses by paper chromatography }\end{array}$ & $\begin{array}{l}\text { Pigments can be extracted by teachers using } \\
100 \% \text { acetone from pigment-deficient } \\
\text { photosynthetic strains and wild type strains. } \\
\text { Spinach extract and cyanobacterial } \\
\text { Phycocyanin powder (Fisher Scientific) can } \\
\text { be used in the paper chromatography } \\
\text { experiment to compare pigments in } \\
\text { phylogenetically separated species. } \\
\text { Chromatography lab can be also connected } \\
\text { with fall leaf color change biochemistry and } \\
\text { carotenoids. }\end{array}$ \\
\hline $\begin{array}{l}\text { 3. Students can observe the red fluorescence } \\
\text { of Phycocyanin solution under cell phone } \\
\text { LED light }\end{array}$ & $\begin{array}{l}\text { Students will learn the oceans can change in } \\
\text { color in summer and winter because of } \\
\text { cyanobacterial bloom concentration and will } \\
\text { know about cyanobacterial pigments: } \\
\text { cyanobacterial pigments, phycocyanin and } \\
\text { phycoerythrin. }\end{array}$ \\
\hline $\begin{array}{l}\text { 4. Photo-taxis lab using Chlamydomonas wild } \\
\text { type strain, lts } 1-211 \text { mutant and rescued lts } 1 \text { - } \\
\text { 211.(Ukei et al. 2016) }\end{array}$ & $\begin{array}{l}\text { lts } 1-211 \text { is an eye spot-less mutant and is } \\
\text { devoid of carotenoids that shows reverse } \\
\text { photo-tactic behavior compared to the wild } \\
\text { type strain in the light. Students can point a } \\
\text { flash light to culture plates of the two strains } \\
\text { and observe the phototaxis pattern of the two } \\
\text { strains. lts } 1-211 \text { moves towards light while } \\
\text { the wild type strain moves away from the } \\
\text { light. Rescued lts } 1-211 \text { will show similar } \\
\text { photo-tactic behavior as the wild type strain }\end{array}$ \\
\hline $\begin{array}{l}\text { 5. Observation of Phototaxis under different } \\
\text { light intensities and redox conditions. }\end{array}$ & $\begin{array}{l}\text { lts } 1-211 \text { mutant moves away from reactive } \\
\text { oxygen species like hydrogen peroxide unlike } \\
\text { the wild type strain. }\end{array}$ \\
\hline 6. Bioinformatics lab & $\begin{array}{l}\text { As described under the Discussion section in } \\
\text { the manuscript. }\end{array}$ \\
\hline 7. Photosynthesis and cellular respiration labs & As described in this manuscript \\
\hline $\begin{array}{l}\text { 8. Advanced Photosynthesis Labs: Testing } \\
\text { different light intensities and different light } \\
\text { color using colored filters (red, blue and } \\
\text { green) }\end{array}$ & $\begin{array}{l}\text { As described under the Discussion section in } \\
\text { the manuscript. }\end{array}$ \\
\hline
\end{tabular}


Table 3 (on next page)

Customization of the photosynthesis lab for college undergraduates. 


\begin{tabular}{|l|l|}
\hline \multicolumn{1}{|c|}{ Activities } & \multicolumn{1}{|c|}{ Comments } \\
\hline $\begin{array}{l}\text { 1. Comparative photosynthesis studies of a } \\
\text { wild type and a photosynthetic mutant strain } \\
\text { using strain-specific algae beads in vials. }\end{array}$ & $\begin{array}{l}\text { Same type of experiment as that described for } \\
4 \mathrm{~A}+\text { and } 10 E 35 \text { in the article. }\end{array}$ \\
\hline $\begin{array}{l}\text { 2. PCR using mutated gene-specific primer } \\
\text { using genomic DNA of the mutant and the } \\
\text { wild type strain }\end{array}$ & $\begin{array}{l}\text { Students can learn how to isolate genomic } \\
\text { DNA }\end{array}$ \\
\hline $\begin{array}{l}\text { 3. DNA gel electrophoresis and agarose gel } \\
\text { extraction of the PCR product }\end{array}$ & Students learn molecular techniques \\
\hline $\begin{array}{l}\text { 4. Cloning of the gel extracted PCR product, } \\
\text { DNA sequencing of the clone and analyses of } \\
\text { DNA sequencing data }\end{array}$ & Students learn molecular techniques \\
\hline $\begin{array}{l}\text { 5. Western blotting to detect presence or } \\
\text { absence of the protein in the wild type and } \\
\text { mutant strains }\end{array}$ & If the protein-specific antibody is available. \\
\hline 6. Bioinformatic labs & $\begin{array}{l}\text { Using various web-based free programs to } \\
\text { perform multi-sequence alignments of } \\
\text { DNA/protein sequences and generating } \\
\text { phylogenetic trees, identifying conserved } \\
\text { domains, studying gene expression and gene } \\
\text { co-expression and generating gene network; } \\
\text { prediction of protein location in cell, learning } \\
\text { to use different gene/protein databases etc. }\end{array}$ \\
\hline $\begin{array}{l}\text { 7. Photosynthetic pigment analyses by } \\
\text { pigment extraction and spectrophotometry; } \\
\text { Paper chromatography or thin layer } \\
\text { chromatography- based labs. }\end{array}$ & $\begin{array}{l}\text { Many photosynthetic mutants are deficient in } \\
\text { chlorophyll and carotenoids. Chlorophyll and } \\
\text { carotenoids can be extracted by 100\% } \\
\text { acetone. }\end{array}$ \\
\hline $\begin{array}{l}\text { 8. Photosynthesis and Non-photochemical } \\
\text { quenching studies using sophisticated } \\
\text { equipment. }\end{array}$ & $\begin{array}{l}\text { Only institutions that have an oxygen } \\
\text { electrode and a PAM fluorometer can perform } \\
\text { these activities. }\end{array}$ \\
\hline
\end{tabular}

